\title{
The Wall Street Rule and its impact on board monitoring
}

\author{
Brandon Chen \\ Victoria Business School \\ Victoria University of Wellington \\ Lien Duong \\ Curtin Business School \\ Curtin University \\ Thu Phuong Truong* \\ Victoria Business School \\ Victoria University of Wellington
}

24 January 2018

*Corresponding author:

Telephone: +64 44635233 (ext. 8961)

Facsimile: +64 44635076

Email: thuphuong.truong@vuw.ac.nz

Keywords: Wall Street Rule; Exit; Board composition; Corporate governance; Stock Price Informativeness

JEL Classification: D82, G14, G23, G32, G34

Acknowledgements: The author thanks Daniel Ferreira, Jarrad Harford, Scott HungChia Hsu, Sigitas Karpaviciusand, Yuen-Hsiang Lin, Hamed Mahmudi, Tom Smith, Peter Swan, Robert Tumarkin, Matthias Thul, Konari Uchida, Ralph A. Walkling, and seminar participants at University of New South Wales, National Taiwan University, Victoria University of Wellington, 2010 FMA Doctoral Student Consortium, $2010 \mathrm{PhD}$ Conference in Economics and Business at Australian National University, and 2010 Australasian Finance and Banking Conference for helpful comments, 2011 FMA Asian Conference, 2011 FMA European Conference. 


\title{
The Wall Street Rule and its impact on board monitoring
}

\begin{abstract}
The "Wall Street Rule" (WSR), a form of monitoring by institutional investors, has been viewed as a "cut-and-run" strategy adopted to express dissatisfaction with a company's management. In this study, we show that WSR, far from being a passive protest, is in fact a potent weapon to improve corporate governance. We present empirical evidence that WSR is positively associated with board monitoring when the firm is endowed with an outsider-dominated board. This suggests that WSR improves stock price informativeness, providing the board with an additional source of information so that it may monitor the company more effectively.
\end{abstract}




\section{Introduction}

Shareholders of a firm that has a dispersed ownership structure often find themselves helpless to influence management over critical decisions. In the absence of large shareholders, few would have incentive to interfere with how the business is run for only a tiny portion of the gains, while bearing the full costs of doing so. Unfortunately, despite having greater holdings of the firm over small shareholders, institutional investors do no better at monitoring, at least in the eyes of academics and shareholder activists. As Jensen (1989) points out, “institutional investors are remarkably powerless; they have few options to express dissatisfaction with management other than to sell their shares and vote with their feet". Following the "Wall Street Rule" or taking a "Wall Street Walk" (also known as engaging in "exit"), hence becomes a byword for shareholder passivism or apathy. ${ }^{1}$

In this study we show that, despite the fact that the "Wall Street Rule" (WSR) has long been viewed as a "white flag" of surrender in the battlefield of corporate governance, it actually increases stock price informativeness. Importantly, it also strengthens the monitoring role of board directors. The traditional agency theories argue that direct intervention (also known as exercising "voice") by large institutional investors is more effective in disciplining a CEO than WSR (see, e.g., Shleifer and Vishny, 1986; Admati, Pfleider and Zechner, 1994). However, recent studies show that WSR, or informed trading by institutional investors, can also be a forceful disciplining mechanism (e.g., Edmans and Manso, 2011). ${ }^{2}$ This study takes one step further and

\footnotetext{
${ }^{1}$ Shareholder activist Robert Monks also points out, "With few options left to them, dissatisfied owners were told by the system to love it or leave." (Ending the Wall Street Walk: Why Corporate Governance Now?) http://www.corpgov.net/forums/commentary/ending.html

${ }^{2}$ Although WSR and "exit" have usually been viewed as selling one's shares only, in this study we adopt the view that, as in Edmans and Manso (2011), investors can both buy and sell depending on the prospect of a firm so that stock prices become informative.
} 
shows that more informative stock prices as a result of WSR can in turn provide board members with a valid source of information to evaluate the CEO. In other words, WSR enhances board monitoring.

Our analysis builds upon recent works on informed trading by institutional investors and its impact on corporate governance. For example, Edmans and Manso (2011) (EM, hereafter) develop a theoretical framework to examine the impact of multiple blockholders (informed traders) on managerial action and firm value. They show that competition for trading profits among informed traders helps impound private information in the stock price. This makes managerial action more transparent to market participants. Knowing that his value-decreasing activities will lead to the sell-off of informed traders (i.e., following WSR) and hence a drop in the stock price (along with a drop in the value of his equity-linked compensation), the CEO would exert more effort aimed at increasing firm value ex ante. In other words, it is the "threat" of WSR, rather than the actual sell-off, that disciplines the CEO. Chen and Swan (2011) (CS, hereafter) extend EM's framework but endogenize the contracting problem, showing that WSR not only leads to a higher level of managerial effort and firm value, but also reduces the use of equity-based compensation (e.g., restricted stocks and stock options). These studies, along with earlier works such as Holmstrom and Tirole (1993), suggest that WSR is by no means a passive way to express dissatisfaction. Rather, it is a potent monitoring mechanism against managers not working in the interests of shareholders.

The motivation of linking WSR to board monitoring is a natural one. The literature on board of directors has thus identified two key sources from which an outside director can learn about the CEO's ability or the quality of a project/business strategy. The first source is the inside directors (those who hold positions in the company), and the other 
is the CEO himself. ${ }^{3}$ Given that institutional investors' trading makes the stock price more informative about managerial action, ${ }^{4}$ it is likely that the overall information environment for board monitoring also improves. Therefore, we posit that stock prices provide an additional avenue for the board to learn about managerial action, in other words, stock price informativness (WSR) complements board monitoring.

We develop a moral hazard-based model based to guide our empirical investigation. The model extends the EM and CS framework, while differing in two respects. First, we introduce the role of board interference. Second, the CEO is now assumed to manipulate the stock price in his favor at the expense of the long-term interests of the firm owners. One of the key features of the model is that we do not claim board monitoring and WSR have to be complements; rather, we discuss when the two mechanisms are more likely to be complements or substitutes. We find that their relation is subject to the initial state of the board independence: if a firm starts with a board dominated by inside directors, then the two mechanisms tend to be substitutes (i.e., WSR mitigates the effectiveness of board monitoring). However, for firms with a board dominated by independent directors (those who are neither affiliated with nor currently employed by the company), the relation is likely to be complementary (i.e., WSR enhances board monitoring). This argument forms the main hypothesis tested by our empirical analysis.

To set up the background for regression analysis, as in the literature, we use the proportion of independent directors sitting on the board (board independence) as a

\footnotetext{
${ }^{3}$ E.g., see Harris and Raviv (2008) and Raheja (2005) for communication/information-transmission between insiders and outsiders and Hermalin and Weisbach (1998), Adams and Ferreira (2007) and Hermalin and Weisbach (2009) for information-transmission between the CEO and outside directors.

${ }^{4}$ It is natural and plausible to assume that only informed traders are able to pose a "threat" to the CEO via WSR. Although informed traders are not necessarily confined to institutional investors, empirical works support the view that institutional investors are likely to hold more information than retail investors (e.g., Parrino, Sias and Starks, 2003; Sias, Starks and Titman, 2006; Aslan, Easley, Hvidkajaer, and O’Hara, 2011); Boehmer and Kelly, 2009).
} 
proxy for board monitoring. We follow Gallagher, Gardner, Swan (2013) and CS, using their "Swing" measure as a proxy for WSR. Specifically, using Thomson Reuter's $13 \mathrm{f}$ filing database, we analyze the trading pattern of each institutional investor for a firm within a year and construct the Swing measure based on a pattern that captures the "monitoring" nature of institutional investors. ${ }^{5}$ We then regress board independence on Swing. If the coefficient on Swing is significantly positive, then both monitoring mechanisms are complements. As in Boone, Field, Karpoff, and Raheja (2007) and Linck, Netter, and Yang (2008), we also estimate the regression using board size as the dependent variable to understand whether WSR can be a factor in determining board size.

We conduct our analyzes on the full sample which consists of S\&P 1500 firms over the period from 1996 to 2007 . The results of the board independence regression support the argument that these two mechanisms are complements. Moreover, the coefficient on WSR remains significant when we include a full array of control variables constructed based on Boone et al. (2007) and Linck et al. (2008), such as complexity of the firm's operation environment, ease of monitoring, managerial incentives, and the perceived ability of the CEO. Most importantly, the results are also robust to the inclusion of firm fixed effects and various approaches to tackling potential endogeneity issues, which are common in the corporate finance literature. ${ }^{6}$ However, we do not find WSR exerts any impact on board size.

There are two regulatory changes in our period of examination 19976-2007: the imposition of a board composed of a majority of independent directors due to the passage of the Sarbanes and Oxley Act of 2002 (SOX) and the ensuring changes in

\footnotetext{
${ }^{5}$ Institutions with more than $\$ 100$ million of securities under management are required to report to the SEC. The Thomson Reuter's 13f filing database contains the aggregate shareholdings for each institution on the quarterly basis. Disclosure is required for all positions greater than 10,000 shares or $\$ 200,000$. ${ }^{6}$ See Wintoki, Linck, and Netter (2011) for discussion.
} 
listing requirements proposed by NYSE and NASDAQ. To investigate the effect of regulatory changes on the relation between WSR and board monitoring, we look at two sub-sample periods: one from 1996 to 2000 (the pre-SOX period), and the other from 2002 to 2007 (the post-SOX period, meaning the period after SOX was enacted and took effect). Since firms were free to choose their board structure in the pre-SOX period, we separate companies of the first sub-sample period into two groups: the compliant ones (those with a board whose independent directors comprising more than $50 \%$ of board members) and the non-compliant ones. By including the non-compliant dummy variable in our estimation, our results shed light on the impact of the initial condition of board monitoring. The results again confirm the complementary relation between the two monitoring mechanisms for compliant firms. But for non-compliant firms, we find that board monitoring is not sensitive to improving price informativeness initiated by WSR. In spite of this, our results show that WSR strengthens board monitoring for non-compliant firms when they turn compliant in the post-SOX period. For the post-SOX period, the regression results are the same as those covered by the full sample period.

This study contributes to the extant literature in three ways. Firstly, to our best knowledge, there is very little literature that recognizes the importance of price informativeness to board monitoring, ${ }^{7}$ despite the fact that the theoretical argument of

\footnotetext{
${ }^{7}$ One exception is Ferreira, Ferreira, and Raposo (2011), which is close to this study in investigating the relation between price informativeness and board structure. However, they argue a substitution relation can arise when more private information is impounded in stock prices (as a heightened takeover threat due to improved price informativeness can offset the usefulness of board monitoring). The seemingly conflicting results between these two studies are due to the definition of "price informativeness". In this article, it is defined as the extent to which true firm value is reflected in stock prices; such definition is also used by Kyle (1985), EM, and Boehmer and Kelly (2009) (which they refer to as informational efficiency of stock prices). According to the theoretical setting in this study, a stock informativeness measure needs to be closely related to trading turnover of informed traders as well as to stock liquidity, for lack of which informed traders would be unwilling to trade on their private information. The Swing variable in use here is motivated by this argument and is computed based on how aggressive informed traders trade. In contrast, Ferreira et al. (2011) use PIN (probability of informed trading) as their proxy for price informativeness in their empirical tests. It is well known that PIN attempts to measure how
} 
WSR facilitating price informativeness has been around for several years (e.g., Holmstrom and Tirole, 1993; Noe, 2002; Admati and Pfleiderer, 2009; EM and CS) and abundant supporting empirical evidence has emerged recently (e.g., see Parrino et al., 2003; Chen, Harford and Li, 2007; Gopalan, 2008; Smith and Swan, 2008; Gallagher et al., 2011). This study argues that WSR is a valid monitoring form and goes further to suggest that board members can benefit from such a monitoring mechanism. This view echoes Gordon's (2007) argument that independent directors gain informational advantage in an environment where stock price informativeness improves so that their ability to monitor the CEO strengthens more than in an environment where prices are less informative. He attributes the improved price informativeness to a better disclosure regime over the past few decades (1950-2005) and an increase in the number of analysts and other institutional investors. Our findings also complement the results reported by Maug (1997) that greater representation of independent directors is the optimal form of monitoring when the costs of acquiring information are low. In particular, we show that board independence indeed increases in an environment where acquiring information about CEO action is less costly (due to increasing informational efficiency of stock prices).

Secondly, our study goes beyond the argument that focuses on the role of stock prices in guiding investment decisions (Dow and Gorton, 1997), stressing that informative stock prices can also be of benefit to board members in carrying out their monitoring

much private information is embedded in stock prices and is negatively correlated with turnover and liquidity (e.g., Aslan et al., 2011). Therefore, Swing and PIN should be negatively correlated. (We find that it is indeed the case.) In other words, the seemingly conflicting conclusions are likely to be two sides of the same coin. In fact, according to Easley, Hvidkjaer and O'Hara (2002), PIN is associated with information risk due to asymmetric information, rather than with price informational efficiency. Our study also differs from Ferreira et al. (2011) in its theoretical motivation: the latter does not consider the source of price informativeness. Finally, Duchin, Matsusaka, and Ozbas (2010) also study the effectiveness of board monitoring and its link to the costs of acquiring information. They find that when the cost of acquiring information is low, firm performance increases when outside directors are added to the board. 
service. But it cannot be successful without a liquid stock market, only in which can informed traders be incentivized to trade on private information at the expense of noise traders (e.g., EM, CS, and Holmstrom and Tirole, 1993). ${ }^{8}$ This study thus enriches the current investigation of the link between informational efficiency of stock prices and determinants of board structure (e.g., Ferreira et al., 2011) by bringing together two strands of literature with one focusing on board structure (e.g., Boone et al., 2007; Linck et al., 2008) and the other focusing on price efficiency (e.g., Boehmer and Kelly, 2009). Finally, this study is a response to the recent call by Adams, Hermalin, and Weisbach (2010) for a better understanding of the relations (substitutes or complements) among various corporate governance mechanisms (e.g., CEO incentives, board monitoring, and takeover threat). Although several studies have been dedicated to this area (see e.g., Coles, Lemmon, and Wang, 2008), few discuss the link between institutional informed trading and board monitoring. This paper shows their relation can be both substitutes and complements, depending on how effective board monitoring for a firm is to begin with.

The remainder of the paper is organized as follows. In Section 2, we develop a simple model on board interference and CEO manipulation. Section 3 describes the data and discusses the rationale of using the Swing measure as a proxy for institutional trader monitoring, along with other control variables. we present empirical results in Section 4. Section 5 discusses the endogeneity issues and other robustness checks. Section 6 concludes.

\footnotetext{
${ }^{8}$ In the same spirit as this article, recent studies provide evidence that stock liquidity (which is central to WSR) bolsters shareholder activism and institutional investor monitoring. See e.g., Edmans, Fang, and Zur (2011) and Norli, Ostergaard, and Schindele (2010).
} 


\section{The model}

We propose a moral hazard-based model to demonstrate that increasing price informativeness due to informed trading can positively affect the effectiveness of board monitoring. This model is a simplified version of the EM or CS theoretical framework but it differs in two respects: firstly, the CEO has incentives to manipulate stock prices; secondly, the board is introduced to monitor the CEO. The model contains two stages. In the first (action) stage, the firm owner (inside shareholder) hires a CEO to run the firm and determine the proportion of independent directors sitting on the board to monitor the CEO on their behalf. In the second (trading) stage, a market maker sets the price given the total order flow submitted by both noise and informed traders as in Kyle (1985). We describe the details in the following sections.

\subsection{The action stage}

In the first stage, risk-neutral firm owners (shareholders) hire a risk-averse CEO to run the firm by specifying an equity-based compensation contract. The CEO chooses the unobservable amount of effort to increase firm value, which has the following representation:

$$
\tilde{v}=\phi_{a} a+\tilde{\eta}
$$

where $a \in[0, \infty)$ represents the unobservable action taken by the CEO, and $\tilde{\eta} \sim N\left(0, \sigma_{\eta}^{2}\right)$ is the normally distributed noise. $\phi_{a}>0$ is the productivity factor, or incremental contribution made by managerial effort.

The CEO's total income, $I$, consists of two parts: a fixed salary $\alpha_{0}$ and an equitybased compensation $\alpha_{p} p$, where $p$ is the publicly observable price, determined by the (competitive) market maker in the trading stage of the game and $\alpha_{p}$ can be interpreted 
as the stock appreciation rights (as in Holmstrom and Tirole, 1993) or equivalently as the pay-for-performance sensitivity (PPS) of the managerial equity-based compensation to firm value. That is,

$$
I=\alpha_{0}+\alpha_{p} p
$$

To boost his compensation, the CEO can influence stock prices in two ways. He can affect the stock price through the choice of his effort level. In addition, pertinent in this study, he can directly engage in unobservable manipulation that puts an upward bias on information signals received by informed traders. Therefore, the use of equity-based compensation acts as a double-edged sword: on the one hand, it brings the interests of the CEO and those of shareholders closer together; on the other, it motivates the CEO to inflate performance signals (e.g., stock prices). ${ }^{9}$

To capture the impact of managerial manipulation on the information obtained by informed traders, we assume that an imperfect "true" signal about the firm value observed by an informed trader takes the form: $\tilde{s}_{i}^{T}=\tilde{v}+\tilde{\varepsilon}_{i}$ if the manager does not manipulate the outcome of the firm, where $i \in N$ denotes the index of each informed trader (there are $N$ such traders) and $\tilde{\varepsilon}_{i} \sim N\left(0, \sigma_{\varepsilon}^{2}\right)$ represents the observational error for each informed trader. After manipulation, the imprecise signal observed by each informed trader becomes $\tilde{s}_{i}=\tilde{s}_{i}^{T}+\omega=\tilde{v}+\tilde{\varepsilon}_{i}+\omega$ instead, where $\omega>0$ denotes the unobservable amount of upward bias due to managerial manipulation and is assumed to be smaller than the firm value, $v$. Following the argument of Goldman and Slezak (2006), managerial manipulation will end up lowering the terminal value of the firm

\footnotetext{
${ }^{9}$ For example, Burns and Kedia (2006) find that the sensitivity of the CEO's option portfolio to stock price is significantly and positively related to the propensity to misreport. Bergstresser and Phlippon (2005) show the periods of high accruals coincide with unusually significant option exercises and unloading of shares by CEOs.
} 
since resources are diverted from long-term to short-term uses. ${ }^{10}$ The realized terminal value of the firm value would then become $\tilde{v}-\xi \omega$, where $\xi>0$ is the incremental resource cost that takes the value 1 in our analysis for simplicity. In other words, the amount of managerial manipulation is assumed to be the same as the amount by which the long-term firm value would be reduced.

To prevent the CEO from manipulating price signals, shareholders choose the board composition, $g \in[0,1]$ (i.e., the level of board independence, or the proportion of independent directors sitting on the board), to monitor the CEO on their behalf. This setting follows the conventional wisdom that the effectiveness of board monitoring increases with board independence, because inside directors are believed to side with the CEO most of the time. ${ }^{11}$ Apart from being a proxy for the effectiveness of monitoring, the degree of board independence, $g$, can also be interpreted as the probability with which the board members would garner information regarding the ability of the CEO (or the compliance of financial disclosure, the quality of a project, etc.). In short, the CEO is more likely to get caught manipulating information when there are more independent directors on the board. ${ }^{12}$

The monitoring service is not free, however. Although we do not explicitly model how firm owners incentivize independent directors, we assume their aggregate cost function takes the form of $0.5 g^{2}$ for convenience. In addition, independent directors can also be motivated by means other than pecuniary compensation. For example, they have

\footnotetext{
${ }^{10} \mathrm{We}$ assume that it costs the CEO nothing to engage in manipulation.

${ }^{11}$ Numerous empirical works show that the presence of independent directors makes board monitoring more effective and reduces the probability of fraud (see e.g., Beasley, 1996; Klein, 2002; Xie, Davidson, and DaDalt, 2003). In addition, Guo (2010) and Cai, Garner, and Walkling (2009) show that the existence of independent directors is related to higher likelihood of CEO turnover.

12 This assumption is not unreasonable given the evidence that probabilities of CEO dismissal have been trending upward (Kaplan and Minton, 2012), which is in line with the trend of more independent boards. Of course, the board can also function as a source of advice and counsel (e.g., Mace, 1971; Adams and Ferreira, 2007; Coles et al., 2008) but in this study we merely focus on the (simplified) role of the board as a monitor on behalf of shareholders.
} 
the desire to honor their fiduciary duty to monitor the manager on behalf of shareholders, or they have reputational concerns (Fama and Jensen, 1983; Maug, 1997)..$^{13}$

\subsection{The trading stage}

In the second (trading) stage of the game, the competitive market maker, noise traders, and informed traders interact to determine the stock price as in Kyle (1985). We follow EM and CS, normalizing the total number of shares to 1 and assuming the free float is fixed and plays no role in this analysis. For the ease of handling the issue of optimal contracting and the determination of equilibrium price at the same time, we further normalize the price on a gross (pre-compensation) basis: $\hat{p}=\alpha_{0}+\left(1+\alpha_{p}\right) p$ as in Holmstrom and Tirole (1993). The normalized managerial income hence becomes:

$$
I=\alpha_{0}+\hat{\alpha}_{\hat{p}} \hat{p}
$$

The interaction of players in the second stage is as follows. Each informed trader observes an imperfect signal about the firm value that is contaminated by an upward bias, $\tilde{s}_{i}$, submitting a market order $x_{i}\left(\tilde{s}_{i}\right)=\kappa+\gamma \tilde{s}_{i}, i \in N$, where $\gamma$ denotes the degree of trade aggressiveness of the informed trader, $\boldsymbol{\kappa}$ some constant. Uninformed noise traders as a group submit a market order $\tilde{u} \sim N\left(0, \sigma_{u}^{2}\right)$. The competitive market maker then sets the market-clearing price equal to expected terminal firm value given the total order flow he observes (without being able to distinguish between the informed and the uninformed order flow): $\hat{p}(\tilde{z})=E[\tilde{v}-\omega \mid \tilde{z}]$, where $\tilde{z}=\sum_{i} \tilde{x}_{i}+\tilde{u}$, the total order flow.

\footnotetext{
${ }^{13}$ Empirical studies on directors' reputational concerns include Gilson (1990), Kaplan and Reishus (1990), Yermack (2004), and Fich and Shivdasani (2007).
} 
We solve this two-stage game by backward induction. We start from the second stage to solve for the equilibrium (normalized) stock price, taking the effort/manipulation level of the manager as well as the board composition as given. Then we return to the first stage to solve for the optimal level of managerial effort and manipulation. Finally, we determine the relevant contracting element $\left(\hat{\alpha}_{\hat{p}}\right)$ and level of board independence ( $g$ ) to maximize the firm owners' expected wealth (i.e., terminal firm value net of compensation to the CEO and board monitoring).

Proposition 1: The equilibrium price has the following linear representations:

$$
\hat{p}=\left(\phi_{a} a^{e}-\omega^{e}\right)-\beta\left(\phi_{a} a^{e}+\omega^{e}\right)+\beta \tilde{s}_{i}+\lambda u
$$

where

$$
\begin{aligned}
& \lambda=\frac{\sqrt{N\left(\sigma_{\eta}^{2}+\sigma_{\varepsilon}^{2}\right)} \sigma_{\eta}^{2}}{\sigma_{u}\left[(N+1) \sigma_{\eta}^{2}+2 \sigma_{\varepsilon}^{2}\right]} \\
& \beta=N \lambda \gamma=\frac{N \sigma_{\eta}^{2}}{(N+1) \sigma_{\eta}^{2}+2 \sigma_{\varepsilon}^{2}},
\end{aligned}
$$

Variables with superscript e in equation (4) take equilibrium values.

Proof: See Appendix.

The results are the same as in CS except that the equilibrium price in equation (4) takes into account the reduction in terminal firm value due to the CEO's diversion of resources. It is important to note that $\beta$ in equation (6) captures price informativeness, which measures the degree to which the true firm value (embedded in the signal, $\tilde{\boldsymbol{s}}_{i}$ ) 
is incorporated in the stock price. ${ }^{14}$ Moreover, it is in direct proportion to trade aggressiveness of informed traders $(\gamma)$ and the number of informed traders $(N)$.

\subsection{Managerial action/manipulation, optimal contracts, and board independence}

We now return to the first stage and solve for the optimal level of managerial effort and manipulation. Consider first the case without managerial manipulation and assume that the risk-averse manager has a negative exponential (constant absolute risk-averse) utility function: $U(I, a)=-\exp \left[-\rho\left(I-\frac{1}{2} a^{2}\right)\right]$, where $\rho$ is the manager's risk-averse coefficient. The cost of managerial effort is assumed to take the quadratic form for convenience. The CEO's problem, as in standard agency models, is to choose the optimal effort in face of the trade-off between the benefit and the cost of exerting effort.

But the CEO's problem is now complicated by his incentives that encourage him to inflate the performance signal, on the one hand, and the possibility of getting caught by board directors, on the other. The optimal level of fraudulent manipulation is dictated by the effectiveness of board monitoring (the degree of board independence, $g$ ), how informed board directors are $(\beta)$, and the probability of detection $(\pi$, introduced immediately below). These three factors constitute the expected penalty that the CEO faces if he gets caught manipulating price signals. Specifically, after learning the relevant information impounded in the stock price (characterized by $\beta$ ), board directors catch the CEO manipulating the performance signal and punish him with probability $\pi$ and the CEO is "fined". Although we do not directly model dismissal of the CEO here, these two scenarios (paying fines and getting fired) are essentially the

\footnotetext{
${ }^{14}$ Price informativeness in this study is formally defined as the expected change in price for a given change in firm value, $E\left[\frac{d \hat{p}}{d v}\right]$. See EM or CS for more detailed exposition on the characteristics of $\beta$.
} 
same if the fines are set to equal the full amount of managerial compensation (including private benefit of acting as a CEO). Combined with the earlier assumption that monitoring effectiveness increases with board independence, the expected fines paid by the CEO due to manipulation is thus $g \cdot \pi \cdot \beta \cdot \omega+(1-g) \cdot 0.15$ This representation guarantees that the "fines" paid by the CEO are proportional to the amount of manipulation discovered by the independent directors through observing the price. For the ease of calculation, we assume that $g$ and $\pi$ are independent of each other, that there is no communication between the $\mathrm{CEO}$ and the board members regarding the true managerial effort/manipulation level, and that the only channel through which board members can learn about managerial action is the relevant information impounded in the stock price. ${ }^{16}$

After considering managerial manipulation and given the features of exponential function and the normal distribution of the managerial income, we take advantage of the mean-variance utility form and write the manager's problem in the following form:

$$
\left(a^{*}, \omega^{*}\right)=\underset{a, \omega}{\arg \max } E(I)-\frac{\rho}{2} \operatorname{Var}(I)-\frac{1}{2} a^{2}-g \pi \beta \omega-\frac{\rho}{2} g(1-g) \pi(1-\pi) \beta^{2} \omega^{2},
$$

where the last two terms specify the expected penalty facing the CEO and the disutility derived from the uncertainty of being caught.

Proposition 2: The optimal level of CEO effort is

$$
a^{*}=\hat{\alpha}_{\hat{p}} E\left(\frac{d \hat{p}}{d v}\right) \phi_{a}=\hat{\alpha}_{\hat{p}} \beta \phi_{a}
$$

\footnotetext{
15 This monitoring technology is à la Becker's (1968) treatment of tax evasion.

${ }^{16}$ This assumption may seem detached from reality as one may argue that (independent) directors can obtain useful information from the CEO. Given the fact that the information released to directors are only as useful as the CEO would like it to be (Adams and Ferreira, 2007), the argument here presents the worst-case scenario in which the only source of information an independent director can rely on in carrying out his monitoring service is public information such as stock prices.
} 
and the optimal level of managerial manipulation is

$$
\omega^{*}=\frac{\hat{\alpha}_{\hat{p}}-g \pi}{\beta \rho g(1-g) \pi(1-\pi)} .
$$

Both equation (8) and (9) highlight the "double-edged sword" feature of granting equity-based compensation to the CEO $\left(\hat{\alpha}_{\hat{p}}\right)$ : although it induces more effort from the CEO, it also leads to higher level of manipulation ( $\omega$ ). As expected, stock price informativeness (as shown earlier in Proposition 1, proportional to the number of informed traders and trade aggressiveness) spurs the CEO to work harder (as demonstrated in EM and CS), while discouraging his from inflating the performance signal.

Finally we consider the optimization problem facing firm owners at the initial stage. Firm owners choose the optimal equity-based pay allocation, $\hat{\alpha}_{\hat{p}}$, and the degree of board independence (or monitoring intensity), $g$, to maximize the firm's terminal value, net of managerial compensation and the directors' costs to gather information. This problem is subject to the manager's incentive-compatibility constraint (IC) and his participation constraint $(\mathrm{P})$ :

$$
\begin{aligned}
& \max _{\hat{\alpha}_{\hat{p}}, g} E\left(\tilde{v}-\omega-I-\frac{g^{2}}{2}\right) \\
& \text { s.t. } \\
& \text { (IC) } a^{*}=\hat{\alpha}_{\hat{p}} \beta \phi_{a} \\
& \text { (IC) } \omega^{*}=\frac{\hat{\alpha}_{\hat{p}}-g \pi}{\beta \rho g(1-g) \pi(1-\pi)} \\
& \text { (P) } E(I)-\frac{\rho}{2} \operatorname{Var}(I)-\frac{1}{2} a^{2}-g \pi \beta \omega-\frac{\rho}{2} g(1-g) \pi(1-\pi) \beta^{2} \omega^{2} \geq \bar{I},
\end{aligned}
$$

where $\bar{I}$ reflects the reservation income of the manager and can be set to zero with no impact on the analysis. 
Innocuous though this model set-up may appear, there is no simple closed-form solution for $g$. Fortunately, the goal of this study is not so much finding the optimal level of board independence as it is finding the impact of price informativeness (due to WSR) on board monitoring, expressed as $\frac{\partial g}{\partial \beta}$, which can be determined by resorting to the implicit function theorem. We form the main hypothesis of our empirical study by assuming $\pi=0.5^{17}$ and treating price informativeness as exogenous to further simplify the optimization problem.

\subsection{Hypothesis development}

The results of applying the implicit function theorem yield the following proposition:

Proposition 3: The relation between board monitoring effectiveness and the Wall Street Rule (WSR) depends upon the initial value of board independence. Board independence and WSR are complements (i.e. $\left.\frac{\partial g}{\partial \beta}\right|_{g_{0}}>0$ ), when the initial value of board independence is high (i.e., $g_{0}$ tends to one); they are substitutes (i.e., $\left.\frac{\partial g}{\partial \beta}\right|_{g_{0}}<0$ ), when the initial value of board independence is low (i.e., $g_{0}$ tends to zero).

We provide the details on the condition for $\frac{\partial g}{\partial \beta}>0$ or $<0$ in Appendix.

While it is true that the sign of the expression $\frac{\partial g}{\partial \beta}$ also depends upon other parameters in the model, the main reason to evaluate this partial derivative at the initial value of $g$ is that the passage of the Sarbanes-Oxley Act of 2002 (SOX) fundamentally changes

\footnotetext{
${ }^{17}$ That is, we assume that the manager would get caught and pay the fines $50 \%$ of the time.
} 
how a firm determines its board composition. SOX, along with ensuing rules adopted by NYSE and NASDAQ, requires the majority of the directors on the board of listed companies to be independent. ${ }^{18}$ This essentially forced all listed companies to adopt an independent director-dominated board by 2003 (see Linck, Netter, and Yang, 2009, or Chhaochharia and Grinstein, 2009 for a detailed account of SOX and its impact on $\mathrm{CEO}$ /director's compensation, directors' workload, and board structure). ${ }^{19}$

Such regulatory change has a direct impact on how effective board directors gather information and monitor the CEO in the model set-up. To take account of the SOX effect, we vary $g_{0}$ from 0.1 to 1 when examining the relation between board monitoring and WSR. Although calibrating $\frac{\partial g}{\partial \beta}$ is not the purpose of this study, to get a sense of how this expression evolves as $g_{0}$ changes, we plug in the values of relevant parameters drawn from the related literature and the dataset in use here. Figures 1 and 2 present the results. The only difference between these two figures is the level of informed trading. In Figure 1, with low level of informed trading, the sign of $\frac{\partial g}{\partial \beta}$ turns from negative to positive when the initial value is around 0.5 , which incidentally is the threshold imposed by SOX. A similar path of the partial derivative is shown in Figure 2, with high level of informed trading.

\footnotetext{
18 The major provisions mandated by SOX and the Self-Regulatory Organizations (SROs-the exchanges) include: (1) The board of directors of each NYSE- and NASDAQ-listed firms must have a majority of independent directors. (2) The independent director must meet a refined definition of independence. (3) The compensation and the nominating/governance committees must consist entirely of independent directors. (4) The audit committee must have a minimum of three members and consist entirely of independent directors. In addition, each member of the audit committee must be financially literate. One member must be an "audit committee financial expert," or the company must disclose that it does not have such an expert and why not (Linck, et al., 2009).

${ }^{19}$ We are aware that the results reported by Chhaochharia and Grinstein (2009) are driven by two outliers in their dataset, as pointed out by Guthrie, Sokolowsky, and Wan (2010).
} 
$<<$ Insert Figure 1 >>

$<<$ Insert Figure 2>>

Proposition 3 forms the main hypothesis of this study: if a company starts with an independent director-dominated board ( $g_{0}$ tends to 1$)$, then there is a positive association between institutional investor monitoring (WSR) and board independence (effectiveness of board monitoring). In other words, these two mechanisms are complements (or WSR enhances board monitoring). However, if a company starts with an insider-dominated board ( $g_{0}$ tends to 0 ), then the association should be negative (i.e., these two monitoring mechanisms are substitutes, or WSR mitigates the effectiveness of board monitoring). The passage of SOX offers a great opportunity to test the hypothesis. Empirically, if the hypothesis is valid, then one should find that WSR strengthens board independence in the post-SOX period as most firms in the sample are forced to adopt an independent board. In contrast, in the pre-SOX period, a negative relation between board independence and institutional investor monitoring should be observed for non-compliant firms.

\section{Data and descriptive statistics}

The dataset is based on the firms belonging to the S\&P 1500, as recorded in the S\&P ExecuComp and the RiskMetrics database (earlier known as IRRC, before it was acquired by ISS in 2005) from 1996 to 2007 . We match this sample to the Center for Research of Security Prices (CRSP) and Compustat databases to arrive at a dataset that unifies information on a firm's board composition, corporate governance, CEO compensation, annual financial data, and stock returns. To make sure the environment in which the sample firms operate is not heavily influenced by political forces and regulations, we restrict the sample to unregulated US firms (by excluding utilities and 
financial firms, i.e., firms with two-digit SIC codes being 49 and 60-69). ${ }^{20}$ To mitigate the issue of outliers, we winsorize continuous variables at the bottom and top $1 \%$. The total sample consists of 7,752 firm-year observations. The details on the definition of the variables of interest are presented in Table 1 and the motivation of choosing these variables is discussed below.

\section{$<<$ Insert Table 1 >>}

\subsection{Board composition and size variables}

The proportion of independent directors sitting on the board (board independence) serves as a good proxy for the effectiveness of board monitoring for several reasons. The calls for a more independent board and board committees from the private or public sectors in the wake of corporate scandals in 2001 and 2002 are aimed to make board monitoring more effective. ${ }^{21}$ The extant literature also assumes the bargaining power of a board increases as its representation of independent directors rises (e.g., Hermalin and Weisbach, 1998). Moreover, related empirical works measure the intensity of board monitoring by board independence (e.g., Weisbach, 1988; Boone et al., 2007; Linck et al., 2008).

The variable Board Independence is generated from RiskMetrics. To be qualified as an independent director according to RiskMetrics, a director must be neither affiliated with nor currently an employee of the company. ${ }^{22}$ We stick to this definition, which is

\footnotetext{
${ }^{20}$ The empirical results still hold when regulated firms are included.

${ }^{21}$ See, for example, Report of the NACD Blue Ribbon Commission on Director Professionalism from National Association of Corporate Directors (NACD) in 1998, or Business Roundtable Statement on Corporate Governance in 2002.

${ }^{22}$ According to the RiskMetrics definition, an affiliated director is a former employee of the company or of a majority-owned subsidiary; a provider of professional services to the company or an executive; a customer or supplier to company; a significant shareholder or a designee under an agreement between the company and a group (e.g., a union); a family member of an executive or an employee; an employee or an organization that receives charitable gifts from the company; or a director who also serves on the board of other companies (interlocking directorship).
} 
stricter than the one adopted by NYSE and NASDAQ, because affiliated directors are generally not viewed as effective monitors due to conflicts of interest (Booth and Deli, 1996; Klein, 1998; Coles et al., 2008b). ${ }^{23}$ We also generate the variable Board Size, defined as the total number of directors on a board, to investigate whether it is associated with WSR.

Panel A of Table 2 shows that mean (median) board size is 9.3 (9) members, with roughly 3 insiders and 6 independent directors (around 66\% of the board size, on average). These numbers are comparable to those found in prior related studies. For example, Coles et al. (2008a) report the median size of board is 10, with about 2 insiders and 8 outsiders, using data from 1999-2003. Bhagat and Black (2001) report a median board of 11 members with 3 insiders, using data for the year 1991. Yermack (1996) finds the median board size is 12 with an insider fraction of $33 \%$ over the period 19841991.

\section{$<<$ Insert Table 2>>}

\subsection{Institutional "swing" measure}

In contrast to several studies using institutional investors' sale of shares as a WSR measure (which essentially captures the actual exit, rather than the threat of exit) and examining its impact on corporate governance (e.g., Parrino et al., 2003; Helwege, Intintoli, and Zhang, 2012), this study emphasizes the "threatening" nature of informed trading by institutional investors. This definition of WSR is adopted in the theoretical framework of EM, CS and this article. After all, from the perspective of corporate governance, it is the competition for profits by informed traders that makes stock prices

\footnotetext{
${ }^{23}$ NYSE and NASDAQ allow former employees to become independent directors if more than three years have passed since the end of their employment. They also allow independent directors to have business relations with the firm as long as the transactions are not significant (Chhaochharia and Grinstein, 2009).
} 
constantly informative, which in turn benefits board members and shareholders, not the one-off sale of shares. As shown in equation (6), price informativeness is proportional to informed trade aggressiveness, a proxy for WSR needs to capture the dynamics of trade aggressiveness. Actual institutional holding data from $13 \mathrm{f}$ filing serves the purpose of this study because one can infer how aggressively an institutional investor trades from changes in his stockholdings. ${ }^{24}$ Following CS and Gallagher et al. (2011), we construct the Swing variable, based on the actual trading patterns of institutional investors, to measure WSR.

We construct the measure of WSR by analyzing all institutional trades in a year. Since the report date of Thomson Reuters $13 \mathrm{f}$ filing database is fixed at every March, June, September, and December, we take every December of the previous year as the starting point and identify a trading pattern by examining the changes in institutional stockholdings for the next three quarters (with each September being the ending point of the last quarter in the year). An increase (decrease) in the stockholdings is treated as a Buy (Sell). For example, if Fidelity increases its holding in Microsoft in March since last December, but decreases its position in June before owning more shares in Microsoft again in September, we conclude that Fidelity engages in a "Buy-Sell-Buy" trading pattern for Microsoft in that year. By examining all institutional trades, we generate eight mutually exclusive trading patterns for each stock in each year: (1) BuySell-Buy (BSB), (2) Sell-Buy-Sell (SBS), (3) Sell-Buy (SB), (4) Buy-Sell (BS), ${ }^{25}$ (5)

\footnotetext{
${ }^{24}$ Several studies use PIN as a measure for price informativeness, which in fact is associated with information risk and negatively correlated with the Swing measure, see Footnote 7. Even as a proxy for "informational risk", PIN is problematic for three reasons. Firstly, as Aslan et al. (2011 ) point out, the maximum likelihood technique used to estimate PIN faces converging issues after the decimalization of tick size in the U.S in 2001. Secondly, PIN seems to fail to capture events considered highly "informative" on many occasions such as M\&A (e.g., Aktas, de Bodt, Declerck, and van Oppens, 2007). Thirdly, as Duarte and Young (2009) point out, PIN at best captures illiquidity unrelated to asymmetric information.

${ }^{25}$ Pattern (3) also includes both Sell-Buy-Hold and Hold-Sell-Buy; pattern (4) also includes Buy-SellHold and Hold-Buy-Sell.
} 
Hold-Hold-Hold (HHH), (6) Buy-Buy-Buy (BBB), (7) Sell-Sell-Sell (SSS), and finally

(8) Others (one occurrence of either Sell or Buy in the sequence, e.g., HSH or BHH).

We require an institutional investor to own the stock for four consecutive quarters for the trade sequence to be valid.

As a stock can experience different trade sequences across institutional investors in any given year, we aggregate for each company all the trading volume of each trading pattern across institutional investors, normalizing this sum by the total number of shares outstanding at the end of each September. In other words, for each firm we compute the turnover rate of each trading pattern. The turnover rate of a stock traded by institutional investors engaging in the BSB or SBS patterns is then termed as "Swing". This is used as a proxy for WSR.

The BSB-derived Swing measure is used as the main testing variable in this study as CS find the BSB pattern best characterizes the "monitoring" or "threat of exit" nature of institutional investors for two reasons. First, BSB pattern illustrates the feature of constant trading among investors, implying that institutional investors closely follow the company. ${ }^{26}$ Second, BSB is the trading pattern that registers the biggest impact of all the trading patterns in their robustness check. They discount the pattern of three consecutive "buy" or "sell" in a year, arguing that it can simply be due to herding, rather than information-based trading.

One can argue that a stock's turnover may also be deemed as a useful proxy for WSR as it captures the constant trading nature of investors (albeit not necessarily wellinformed ones). Indeed, the correlation between the market turnover of a stock (defined

\footnotetext{
${ }^{26}$ In the context of the Australian market, Gallagher et al. (2011) show that BSB and SBS trading patterns, based on the daily trading data from a representative sample of fund managers, result in subsequent firm outperformance. The swing trade is profitable even after taking into account transaction costs. However, profitability declines with the number of fund managers. This suggests fund managers trade on a highly-correlated signal about the future firm value.
} 
as the ratio of the firm's trading volume to its total number of shares outstanding) and the BSB-derived Swing measure is $35 \%$. However, when the market turnover measure is included as an explanatory variable in the core regression models of this study (discussed in Section 3.3.4 below) along with the BSB-derived Swing measure, it loses statistical significance to the Swing measure (results unreported here).

Panel B of Table 2 presents the summary statistics for the firm's turnover rate by each of the trading patterns mentioned above and the total institutional turnover. ${ }^{27}$ The mean of the total institutional turnover is about $27 \%$ with a standard deviation of $13 \%$ and the mean turnover of all the trading patterns is $3.9 \%$, varying from $0.16 \%$ (represented by the "Sell-Buy" pattern) to $13.4 \%$ (the "Others" pattern).

\subsection{Control variables}

We rely on the recent literature to generate control covariates in this study. These covariates are all based on the existing theories and deemed to be important determinants of corporate boards. Here in the following subsections we summarize the three major hypotheses categorized by Boone et al. (2007).

\subsubsection{The scope of operations hypothesis}

This hypothesis posits that board structure is driven by the scope and complexity of the firm's operations. Fama and Jensen (1983) argue that a firm with a larger or more complex production process or with geographically dispersed operations would require more information; a larger board with more outside directors may be more suitable in addressing the needs of such a firm. Lehn, Patro, and Zhao (2009) and Coles et al.

\footnotetext{
${ }^{27}$ No turnover rate for the trading pattern "HHH" as there is no change in holdings.
} 
(2008a) share this view and argue further that diversified firms deploy more independent directors to monitor their wide scope of operations.

The hypothesis predicts that both board size and board independence are positively associated with firm size (measured by the natural log of sales), firm age (measured by the natural $\log$ of number of months since the firm first appears on CRSP), and the number of business segments. As in Coles et al. (2008a) and Linck et al. (2008), we also include the debt ratio as an additional proxy for the advising benefits brought by outside directors.

As can be seen from Panel $\mathrm{C}$ of Table 2, the average (median) sales of the sample firms is about $\$ 5.6(\$ 1.7)$ billion; this figure is highly right-skewed: the $75^{\text {th }}$ percentile firm has sales of $\$ 4.97$ billion. More than $50 \%$ of the firms operate in more than three business segments. Median leverage is 0.22 and the average age of the sample firms since they first appeared on CRSP is about 25 years.

\subsubsection{The monitoring hypothesis}

The monitoring environment of a firm also affects board structure. When the costs of monitoring increase, for example, due to greater information asymmetry (Maug, 1997), more sophisticated firm-specific knowledge or higher growth opportunities (Coles et al., 2008a), noisiness of operating environment (Demsetz and Lehn, 1985), or the freerider problem arising from boards of large size (Raheja, 2005; Harris and Raviv, 2008), monitoring services provided by an outsider-dominated or large board may be reduced or ineffective. On the other hand, board size and board independence may rise when the net benefits of extra monitoring increase (due to the manager's opportunities to consume private benefits). 
This hypothesis thus predicts that board independence and board size should increase with the net benefits of monitoring, and decrease with the costs of monitoring. To measure the monitoring costs to outsiders, we use the log of the market-to-book ratio, R\&D expenditures, and (previous-year) standard deviation of stock returns. The first two are standard measures of growth opportunities (Smith and Watts, 1992; Gaver and Gaver, 1993; Coles et al., 2008a), whereas the last one is for the noisy operating environment of a firm, or for information asymmetry (Linck, et al., 2008). To measure the net benefits of monitoring (or equivalently, the manager's opportunities for private benefits), we include proxies of free cash flow, FCF (Jensen, 1986), and industry concentration (Gillan, Hartzell, and Starks, 2011). These variables are defined in detail in Table 1.

We also include pay-for-performance sensitivity (PPS) of the CEO's total equitybased (including both stocks and stock options) compensation (PPS_Total) in the analysis. Higher CEO ownership implies closer alignment of interest between the manager and shareholders; the CEO would be less likely to extract private benefits at the expense of shareholders. This in turn, as suggested by Raheja (2005), reduces the need for outsider monitoring, leading to a smaller and less independent board.

Panel D of Table 2 presents the summary statistics of the variables derived from monitoring cost hypothesis. The adjusted market-to-book ratio averages -2.06 ; more than $25 \%$ of the firms have unreported R\&D expenditures. The CEO's total holdings of options and stock would increase about $\$ 35$ for every $\$ 1000$ increase in shareholder value. The free cash flow proxy averages $8.3 \%$, almost identical to the number reported by Coles et al. (2008) using the data from 1992 to 2001.

\subsubsection{The negotiation hypothesis}


Hermalin and Weisbach (1988) suggest that board independence decreases with the CEO's bargaining power - if the CEO shows he is capable of generating surpluses for his firm, he has greater influence over the selection of board members. To measure the CEO's perceived ability, we use past performance $\left(R O A_{t-1}\right)$ and the log of CEO tenure (Linck et al., 2008). Note that this hypothesis does not predict how the board size would change.

Finally, we also include the ownership concentration of the five largest institutional investors (Top5_shrout) as an additional control variable to proxy for direct intervention by institutional investors (Chen, Harford, and Li, 2007). Traditional agency theories predict that large institutional investors with concentrated ownership have incentives to monitor the manager through direct intervention (Shleifer and Vishny, 1986; Admati, Pfleider and Zechner, 1994; Kahn and Winton, 1998). By controlling for concentrated institutional ownership, we essentially raise the bar for Swing to explain its relation to the structure of the board.

Panel E of Table 2 shows that the sample firms' ROA averages $4.8 \%$ for the observation period, 1992-2007. Mean and median CEO tenure is 7.2 and 5 years, respectively, comparable with the numbers reported by Linck et al. (2008) and Coles et al. (2008). The former reports 7.1 and 5.0 years, and the latter 6.6 and 5.0 years, for the mean and median CEO tenure, respectively. Both studies cover the period of the 1990s to the early 2000 s.

\subsubsection{The core testing models}

The core regression models have the following specifications: 


$$
\begin{aligned}
& \text { BoardIndep }_{i t}=\beta_{0}+\beta_{1} \text { Swing }_{i t}+\beta_{2} \ln (\text { Sales })_{i t}+\beta_{3} \text { Debt_Ratio }_{i t} \\
& +\beta_{4} \ln (\text { NumSegments })_{i t}+\beta_{5} \ln (\text { FirmAge })_{i t} \\
& +\beta_{6} \text { Market-to-book }_{i t}+\beta_{7}(\mathrm{R} \& \mathrm{D} / \mathrm{A})_{i t}+\beta_{8} \text { Ret_ }_{-} \text {olat }_{i t-1} \\
& +\beta_{9} \text { PPS _ } \text { Total }_{i t}+\beta_{10} F C F_{i t}+\beta_{11} \text { IndustryHerfindahl }_{i t} \\
& +\beta_{12} \text { ROA }_{i t-1}+\beta_{13} \ln (\text { CEOTenure })_{i t}+\beta_{14} \text { Top } 5_{-} \text {shrout }_{i t}+\varepsilon_{i t} \\
& +\beta_{4} \ln (\text { NumSegments })_{i t}+\beta_{5} \ln (\text { FirmAge })_{i t}+\beta_{6} \text { Market-to-book }_{i t} \\
& +\beta_{7}(\mathrm{R} \& \mathrm{D} / \mathrm{A})_{i t}+\beta_{8} \text { Ret_Volat }_{i t-1}+\beta_{9} \text { PPS_Total }{ }_{i t}+\beta_{10} F C F_{i t} \\
& +\beta_{11} \text { IndustryHerfindahl }_{i t}+\beta_{14} \text { Top5 } 5_{-} \text {shrout }+\varepsilon_{i t}
\end{aligned}
$$

The coefficient of interest is $\beta_{1}$ in both equations, which captures the effect of WSR (proxied by Swing) on board structure. We include industry (two-digit SIC) and year dummy variables in both specifications. The main difference between the two equations is that we remove the variables derived from the negotiation hypothesis from equation (12) as it does not apply to the determination of board size. Moreover, $R \& D / A$ suffers the most from the missing values. Simply discarding firm-years with missing values would result in a huge reduction in the sample size and the introduction of self-selection bias. We follow the approach adopted by Himmelberg, Hubbard, and Palia (1999) in dealing with missing data by setting the missing values of the variable in question to 0 and including a dummy that equals 1 when data are missing, and 0 otherwise. To adjust for potential model misspecifications, we use robust methods (Huber/White estimator) to compute standard errors and we also cluster the standard errors at the firm level to adjust for within-firm correlation (Petersen, 2009).

\section{Empirical evidence}

\subsection{Main results on non-compliant vs. compliant firms: the pre-SOX period}

Since nearly all firms in the dataset are compliant with the SOX requirements for board composition after 2002, to directly test the hypothesis derived from Proposition 
3, we first examine the pre-SOX period, during which companies remain free to choose their own board structure.

We separate the sample firms into two groups in the pre-SOX period-compliant and non-compliant firms-by creating a non-compliant dummy (Non-compliant) that equals 1 if the majority of the directors on the board are not independent and zero otherwise. To make sure this sub-sample period is adequately free from the influence of SOX,$^{28}$ we use the year 2001 as the cut-off year and define 1996-2000 as the preSOX period. The year 2000 is still regarded a year less affected by the sentiment calling for a more independent board. The choice of the cut-off year is also in line with Linck et al. $(2008,2009)$.

Table 3 compares the characteristics of firms that were compliant and non-compliant with the SOX requirements in 1996, 1998, and 2000, respectively. We find noncompliant firms are generally smaller, younger, and more complex (in terms of number of business segments) than compliant firms. This finding is in line with the results presented by Lehn et al. (2009), Boone et al. (2007), and Linck et al. (2009) that smaller firms are less likely to be compliant with SOX. In addition, non-compliant firms may suffer more agency problems than compliant firms because they face a more uncertain operation environment (higher return volatility, also a proxy for information asymmetry), and their CEO may be more entrenched or have more perceived power (due to longer tenure or higher equity ownership). Alternatively, a higher PPS may be used to substitute for a relatively weak board. Importantly, there is no significant difference in Swing between the two samples, suggesting that institutional investors have no preference for either type of firm when they trade on information. This gives

\footnotetext{
${ }^{28}$ Although SOX took effect in 2002, many companies increased the representation of independent directors many years before the introduction of SOX, possibly under the pressure from shareholder activists and institutional investors (Linck et al., 2009).
} 
us some confidence that the WSR proxy is likely to be an exogenous variable in the board composition regression. ${ }^{29}$

Table 4 presents the results from the core regressions on board independence and board size with the inclusion of Non-compliant dummies and the interaction terms of Non-compliant with all the regressors. If Proposition 3 is correct, then we expect to find the coefficient on Swing to be positive and the interaction of Non-compliant with Swing to be negative. We use one-period lag of Non-compliant dummies to capture the initial condition of the effectiveness of board monitoring in Proposition 3. Column 1 of Table 4 reports the results of using Swing as the only explanatory variable. The results show that Swing is indeed associated positively and significantly with board independence. The sign of the interaction term is negative, as predicted by the model, although the coefficient is not statistically significant. This suggests that greater institutional investor monitoring is associated with higher board independence for the compliant firms, but not for the non-compliant firms.

In Column 2 of Table 4 we include other control variables and their interaction terms with Non-compliant dummies in the regression specification. The results are similar to those reported in Column 1: the coefficient on Swing remains significantly positive, whereas the coefficient on the interaction term of Non-compliant and Swing remain negative but insignificant. The inclusion of the full array of control variables based on extant theories cannot explain the significant association between Swing and Board independence.

$$
<<\text { Insert Table 4>> }
$$

\footnotetext{
${ }^{29}$ To make sure our findings below are not driven by reverse causality, we regress Swing on Board Independence, along with other variables regarded as determinants of institutional trading (see, e.g., Gompers and Metrick, 2001; Yan and Zhang, 2009). The coefficient on Board Independence is not significantly different from zero.
} 
In order to avoid the potential issue of mutlicollinearity arising from using several related variables (namely, sales, leverage, the number of business segments, and firm age $)^{30}$ to proxy for complexity and the CEO's need for advice, we follow Coles et al. (2008a) and use the method of common factor analysis ${ }^{31}$ to capture the underlying commonality among these variables. The key advantage of common factor analysis is to reduce the number of dimensions of the variables and extract the latent factor(s). we term the extracted factor "ADVICE", as do Coles et al. (2008a) in their studies, although they do not consider firm age in their factor analysis. ${ }^{32}$ In Column 3 of Table 4 we replace the four variables related to complexity with the ADVICE factor score in the regression on board independence. As predicted by the scope of operations hypothesis, the coefficient on the ADVICE factor score is positive and significant at the $1 \%$ level. However, the coefficient on its interaction term with Non-compliant is negative and significant. This suggests that non-compliant firms, unlike their compliant counterparts, tended not to increase board independence in the pre-SOX period even when they had a greater scope of operations.

In terms of economic significance, one standard-deviation increase in Swing would increase Board Independence by about $1 \%$ for an average firm. For comparison purposes, we also calculate the economic significance for other significant control variables. For example, the magnitude of increase (decrease) in Board Independence is

\footnotetext{
30 The highest correlation is between Ln_Sales and Ln_FirmAge (47.5\%), the lowest is between Debt_Ratio and Ln_FirmAge (12.1\%).

31 Since the observed variables in our case (e.g., firm age, sales, etc.) are merely proxies for the latent (unobserved) complexity of a firm, some measurement error is likely to exist. Common factor analysis is more appropriate in data reduction than principal component analysis is. The latter is implemented by Coles et al. (2008a).

${ }^{32}$ Wealso run the factor analysis on the variables related to the costs of monitoring (i.e., market-to-book, R\&D expenditures, and return volatility); however, the correlation among these variables appears to be too low to extract a meaningful factor. Indeed, the communality estimates are relative low compared with the estimates on "ADVICE" variables.
} 
$4.3 \%,(-0.7 \%)$, and $2.9 \%$, for one standard-deviation increase in score_ADVICE, Ln_CEOTenure, and Top5_Shrout, respectively.

In sum, although our empirical results do not concur with the strong prediction that WSR and board independence are substitutes when the firm is initially non-compliant, they do support the argument that both mechanisms are complements when the firm is compliant. Put differently, the empirical evidence suggests that, given an independent director-dominated board, board directors are more effective in monitoring when the information environment improves. Conversely, if the firm starts with an insiderdominated board, then even an improving information environment (due to more informative stock prices) would not help board directors very much in monitoring.

Columns 4-6 of Table 4 re-do the analysis as in Columns 1-3 using board size as the dependent variable, instead. We find there is no association between WSR and board size, regardless of compliance. With regard to control variables, the results for compliant firms are the same as extant theories suggest. But the inclusion of a noncompliant dummy has no impact on the relation between board size and control variables, either.

\subsection{Main results after the passage of SOX (2002)}

In this section we examine the relation between board composition and WSR after the passage of SOX, using data from 2002 to 2007. As most firms have turned compliant since 2002 (We do not need to separate non-compliant firms from compliant ones), ${ }^{33}$ we expect to see a significant and positive association between Swing and Board independence.

The results in Table 5 confirm this hypothesis. Column 1 reports the results of estimating the restricted regression model, whereas Column 2 includes other control

\footnotetext{
${ }^{33}$ Indeed, more than $85 \%$ (90\%) of sampled firms turned compliant in 2002 (2003).
} 
variables. The coefficients on Swing in both specifications are indeed positive and significant. Column 3 is similar to Column 2 except that it replaces the four complexityrelated variables with the factor extracted from common factor analysisscore_ADVICE; the results remain the same. The sign of the coefficients on other significant controls (e.g., score_ADVICE, Lag_Ret_Volat,PPS_Total) is the same as in the previous literature.

$$
<<\text { Insert Table 5 >> }
$$

Columns 4-6 of Table 5 report the results on board size regression. However, we do not find Swing is significantly associated with board size in a consistent manner.

To make the exposition of our results clearer, here and throughout, we use the ADVICE factor score, instead of the four complexity-related variables, in our estimation. $^{34}$

\subsection{Main results: non-compliance and the post-SOX effect}

Although improving information environment due to WSR does not seem to affect board monitoring for non-compliant firms in the pre-SOX period, is it possible that as these firms turn compliant after SOX, WSR starts making board monitoring more effective? To answer this question, we utilize the sample from $1998-2007,{ }^{35}$ choosing 2003 as the cut-off point for POSTSOX dummy, and construct the following regression specification with multiple interaction terms:

\footnotetext{
${ }^{34} \mathrm{We}$ also estimate the models using the individual variables in all cases and the results are not affected at all.

${ }^{35}$ We ignore observations in 1996 and 1997 in order to have a similar number of observations in the preand post-SOX periods. The results remain the same when observations in 1996 and 1997 are included.
} 


$$
\begin{aligned}
\text { BoardStructure } & =\beta_{0}+\beta_{1} \text { Swing }+\beta_{2} \text { Swing } \times \text { POSTSOX } \\
& +\beta_{3} \text { Swing } \times \text { Noncompliant } \\
& +\beta_{4} \text { Swing } \times \text { POSTSOX } \times \text { Noncompliant } \\
& +\delta \text { POSTSOX }+\chi \text { Noncompliant }+ \text { Controls }+\varepsilon,
\end{aligned}
$$

where POSTSOX is a dummy variable that takes the value of one if the sample year falls after 2003 and zero otherwise. ${ }^{36}$ Non-compliant is also a dummy variable, with the same definition as mentioned above (with one lag), and BoardStructure, is either Board Independence or Board Size. On relevant coefficients, $\beta_{1}$ captures the effect of WSR on board structure for compliant firms in the pre-SOX periods. $\beta_{2}$ is the incremental effect of WSR on board structure for compliant firms in the post-SOX period. $\beta_{3}$ is the incremental effect of WSR for non-compliant firms in the pre-SOX period. $\beta_{4}$ is the incremental effect of WSR for non-compliant firms in the post-SOX period. The total effect of WSR on board structure for initially non-compliant firms in the post-SOX period is captured by the sum of the above four coefficients (i.e., $\beta_{1}+\beta_{2}+\beta_{3}+\beta_{4}$ ).

Column 1 and Column 4 of Table 6 present the results of estimating equation (13) with Board Independence and Board Size as the dependent variable, respectively. As expected, the POSTSOX dummy is positively and significantly related to Board Independence, indicating corporate boards indeed become more independent postSOX. However, we find that the POSTSOX dummy is negatively related to Board

\footnotetext{
${ }^{36}$ The reason to use 2003 as the cut-off year in this section is as follows: Although SOX was enacted on July 30, 2002, firms were not required to comply with the new listing requirements until 2004. Specifically, NYSE and NASDAQ required firms to adopt new listing rules during their first annual meeting after 15 January 2004 but no later than October 31, 2004. Firms with classified (staggered) boards can delay adopting the rules until the second annual meeting but no later than 31 December 2005 (Chhaochharia and Grinstein, 2009). In addition, Chhaochharia and Grinstein (2009) find the largest annual increase occurs between 2002 and 2003. The results reported in Section 4.2 (in the post-Sox periods, starting from 2002 onwards) still hold even if we use the period from 2003 onwards instead.
} 
Size. ${ }^{37}$ The results on all the other coefficients are similar to the earlier findings in this study; the coefficient on Swing remains positive and significant in the board independence regression, but not significant in the board size regression.

\section{$<<$ Insert Table 6>>}

The next step is to investigate whether the complementary relation between Swing and board structure is significantly different in the post-SOX period compared with the pre-SOX period. Column 2 of Table 6 presents the results of the board independence regression. We find the coefficient on Swing positive and significant (albeit at the $10 \%$ level) but the coefficient on its interaction term with POSTSOX insignificant. This indicates that the positive association between WSR and board independence is stronger before SOX than after the passage of SOX. However, we can reject the hypothesis that the sum of the above two coefficients equals zero ( $p$-value $<0.01$ by the $F$-test). This suggests that more aggressive informed trading by institutional investors is linked to a more independent board in both periods, but the relation is unchanged by SOX. This is another confirmation of the conclusion drawn from both Table 4 and Table $5 .^{38}$

Column 3 of Table 6 reports the results of estimating the regression model (13). The coefficient on the interaction term of Swing with POSTSOX and Non-compliant is significantly positive at the $1 \%$ level, suggesting that WSR indeed strengthens board independence for the initially non-compliant firms when they turn compliant in the post-SOX period. The total effect of WSR on board independence for such firms is also

\footnotetext{
${ }^{37}$ It is important to note that SOX does not have any direct mandate regarding board size and the general trend from 1998 to 2005 is relatively stable compared with the a significant rising trend for board independence (Linck et al., 2009, p.3313). Indeed, we find the combined intercept (10.4) for the postSOX period is not significantly different from the mean board size (which is 9.31 with standard deviation equal to 2.5, as reported in Table 2) from 1996-2007.

${ }^{38}$ The result is also related to the fact that most firms (more than $75 \%$ ) have already adopted an outsiderdominant board in the pre-SOX period; hence the complementary relationship between Swing and Board Independence dominates. Wedistinguish this effect in Table 4 and Table 5.
} 
significantly positive $\left(\hat{\beta}_{1}+\hat{\beta}_{2}+\hat{\beta}_{3}+\hat{\beta}_{4}=70.92, p\right.$-value=0.0169). This finding lends further support to the argument that WSR reinforces board monitoring for firms with a strongly independent board.

The results on other coefficients regarding Swing are similar to earlier findings. Despite that the coefficient on the interaction term of Swing and Non-compliant (preSOX) is significantly negative, the total effect of WSR on board independence for such firms $\left(\hat{\beta}_{1}+\hat{\beta}_{3}\right)$ is indistinguishable from zero, in line with the results in Table 4. Again, SOX has no impact on the relation between WSR and board structure, as the coefficient on (Swing X POSTSOX) shows. For brevity, we do not include interaction terms of control variables with POSTSOX and Non-compliant in estimating the regression. Nonetheless, the findings are exactly the same when interaction terms are considered.

Columns 5 and 6 of Table 6 report the results of the board size regression including the interaction terms. Again, we do not find any association between Swing and board size.

Taken together with the results reported in Table 4 and Table 5, we find that, with an independent director-dominated board, board monitoring proxied by board independence does indeed improve when the stock price becomes more informative as a result of WSR. This is the case before 2000; this is also true after 2002. Although we do not find that WSR as a monitoring mechanism substitutes board monitoring for noncompliant firms in the pre-SOX period, we find that it has no impact on the effectiveness of board monitoring for such firms, nonetheless. That said, our analysis reveals that WSR starts strengthening board monitoring when these firms are forced to adopt a strongly independent board after SOX. 
The empirical results support our hypothesis. We also find WSR exerts no impact on board size, regardless of the passage of SOX. From here forward, we focus only on the board independence regression ${ }^{39}$ and utilize all observations from 1996-2007 to take advantage of the full-sample dataset.

\section{Robustness checks}

In this section we discuss the issue of endogeneity and the empirical results generated by using alternative measures for institutional investor monitoring and board monitoring. We also discuss whether having anti-takeover provisions in place would affect the main findings shown above.

\subsection{Endogeneity}

Up to this point we have been using OLS regressions in our empirical analyses. One of the key assumptions behind the OLS approach is strict exogeneity, which dictates that the error terms are strictly independent of all past and future values of the independent variables. As noted by Linck et al. (2008) and Wintoki et al. (2012), although in corporate finance research the error terms and the independent variables might be unrelated contemporaneously, such a relation may not hold, however, for all the past values of the independent variables (e.g., current board structure is strongly related to past firm performance if one intends to regress firm performance on board sturcutre). Luckily, in our case such a "dynamic endogeneity" issue ${ }^{40}$ is less pronounced since the explanatory variables (firm characteristics in our setting) are not strongly determined by the lagged values of board independence (the dependent

\footnotetext{
${ }^{39}$ Considering the following specifications or robustness tests does not alter the relation between WSR and board size.

${ }^{40}$ The term is used by Wintoki et al. (2011).
} 
variable) as evidenced by Wintoki et al. (2012). ${ }^{41}$ Nonetheless, two other sources of endogeneity still remain: unobservable heterogeneity (which arises if there are unobservable factors affecting both the dependent and explanatory variables) and simultaneity (which arises if the independent variables are a function of the dependent variable or the expected values of the dependent variable). ${ }^{42}$ In this section, we aim to tackle endogeneity using several approaches.

One way to mitigate (but not entirely eliminate) the problem of unobservable heterogeneity is to use fixed effects to estimate the regression models. We have been using year and industry fixed effects in all the analyses thus far; in this section we consider all the time-invariant firm characteristics by including firm fixed effects in the estimation. Column 1 of Table 7 presents the results of the board independence regression including firm fixed effects. The R-squares increase substantially to $77.3 \%$ from $26.4 \%$ (Column 1 of Table 7, over the same observation period), indicating the inclusion of the time-invariant firm characteristics indeed boosts the explanatory power of the model. More importantly, the coefficient on Swing remains positively significant at the $5 \%$ level.

We also use the two-stage least squares (2SLS) regressions to address endogeneity. To derive consistent estimates, an instrumental variable (IV) must satisfy two conditions: it must be highly correlated with the endogenous variables (Swing, in this case) and uncorrelated with the error terms. We use the natural log of analyst coverage (Ln_AnalystCov) as an instrument for Swing. The analyst coverage variable is sourced

\footnotetext{
${ }^{41}$ Admittedly, a few variables in the specification may still be affected by the past values of board structure such as CEO's equity-based compensation (PPS_Total).

${ }^{42}$ The issue of simultaneity or reverse causality perhaps is less egregious in this study since there is no significant difference in the intensity of institutional investor trading between firms with outsider- and those with insider-dominated boards, as is shown in Table 3. In other words, informed traders are less likely to trade more aggressively simply because a firm has a more (or less) independent board. In addition, as noted earlier, we do not find reverse causality in our regression analysis. Helwege et al. (2012 ) report no impact of board independence on institutional blockholding, either.
} 
from the $\mathrm{I} / \mathrm{B} / \mathrm{E} / \mathrm{S}$ historical summary statistics files, computed as the (log) number of analysts who provide the forecast of EPS one year ahead for a firm.. The economic rationale for this choice is related to price transparency: more information should be impounded in stock prices if the firm is followed by more analysts because they are likely to turn private information into public information. Moreover, there is no prior evidence or argument that shows that the number of analysts covering the firm should be considered a determinant of board composition. Since both Ln_AnalystCov and Swing can lead to a greater degree of price transparency and efficiency, we expect these two variables to be positively correlated. Indeed, the Pearson correlation of Swing with Ln_AnalystCov is $12.4 \%$ (statistically significant at the $1 \%$ level).

$$
<<\text { Insert Table 7 >> }
$$

Column 2 of Table 7 reports the results of the first-stage regression that uses Swing as the dependent variables; all the control and instrumental variables are treated as "excluded" instruments. It is certainly found that the chosen instrumental variable is positively and significantly related to Swing. The null hypothesis that the instrumental variable can be excluded from the first-stage regression is strongly rejected at the $1 \%$ level by the $F$-test (the $F$-statistic=97.39). This indicates that our 2SLS estimates in the second stage will not be driven by weak instruments. Column 3 of Table 7 presents the result of the second-stage regression and we find the coefficient on Swing is again positive and significant (albeit at the $10 \%$ level).

Although simultaneity does not seem to pose a serious problem in this study, to be certain that our results are robust to specifications aimed at alleviating simultaneity we conduct two more analyses. Following Coles et al. (2008a) and Hermalin and Weisbach (1991), we use lagged values (instead of the current values) of explanatory variables in 
the regression. We report the result in Column 4 of Table 7. We also follow Dahya, Dimitrov, and McConnel (2007) and Rajgopal and Shevalin (2002) and use the lagged value of the dependent variable as the new dependent variable, but keep the right-hand side variables intact. Column 5 of Table 7 presents the results. In both cases, the coefficients on Swing are still positive and significant.

\subsection{Alternative measures for institutional investor monitoring}

Thus far we have been following CS and using the "Buy-Sell-Buy (BSB)" trading pattern of institutional investors to proxy for WSR, as they show that this particular pattern yields the most significant results over the other patterns in their analysis. Admittedly, this is merely one way of capturing the "threatening" nature of WSR. In this section, we adopt two alternative measures to examine the robustness of the claim that institutional trader monitoring is positively associated with board independence. The first one is based on the number of informed institutional investors, while the second one takes into account the heterogeneity of institutional investors.

Our first alternative measure is the number of informed institutional traders. As Equation (6) shows, stock price informativeness increases with the number of informed traders. We count the number of such institutional investors for a firm and take the natural log to generate the $L n \_N u m \_M g r$ variable, based on the argument of CS and Gallagher et al. (2011) that the institutional investors engaging in the BSB trading sequence are most likely to be informed traders. Table 8 presents the results of using measures alternative to Swing. In Column 1 we still use Swing as the main proxy for institutional investor monitoring as a reference; the only difference between this result from the previous ones is here we use the full sample period from 1996 to 2007 . The coefficient on Swing is still positively significant. Column 2 shows the result of using 
Ln_Num_Mgr instead of Swing. The coefficient on this alternative measure indeed is positive and significant.

\section{$<<$ Insert Table 8>>}

We are also aware that neither the Swing nor the $L n \_N u m \_M g r$ measure takes into account the heterogeneous nature of institutional investors, a fact that is well noted in the literature (e.g., Gompers and Metrick, 2001; Bennett et al., 2003; Yan and Zhang, 2009). To resolve this issue, we resort to an entirely different methodology to classify institutional investors as per Bushee $(1998,2001) .{ }^{43}$ Bushee's classification tackles heterogeneity in institutional investors by examining their investment horizon and portfolio diversification. He classifies institutions into three types: transient institutions (TRA) have high portfolio turnover and diversified portfolios. Dedicated institutions (DED) have low turnover and more concentrated portfolio holdings. Finally, quasiindexer institutions (QIX) have low turnover and diversified portfolio holdings. ${ }^{44}$ Of the three types, we expect transient institutions to be closely related to the Swing traders defined in this study because they are more likely to be constantly covering the invested firms than the other two types. Indeed, we find the correlation between the Swing and the turnover rate of transient investors is $43.3 \%$, compared with $38.8 \%$ and $17.3 \%$ with the turnover rate of quasi-indexer and dedicated institutions, respectively (all statistically significant at the $1 \%$ level). We thus use turnover of the transient investors (Turnover_TRA) as the second alternative to Swing.

\footnotetext{
${ }^{43}$ Bushee uses principal factor analysis and cluster analysis to classify institutional investors into three groups based on their past investment behavior and portfolio characteristics. Eight variables are constructed to describe the investment behavior of institutional investors. See Bushee $(1998,2001)$ for details.

${ }^{44}$ The authors thanks Brian Bushee for making his classification data public on his website.
} 
As can be seen from Column 3 of Table 8, the coefficient on Turnover_TRA is also positive and significant (at the $1 \%$ level), indicating that our findings are robust to alternative proxies for WSR.

\subsection{Adoption of antitakeover provisions}

Our investigation on the relation between board structure and institutional investor monitoring up to this point has controlled for several governance mechanisms (i.e., CEO's incentive scheme, the use of debt, and activism by large shareholders) and firm characteristics. However, it is also possible that certain antitakeover provisions adopted by a firm can affect the complementary relation between board independence and WSR since the takeover threat and board independence are likely to be substitutes in disciplining the CEO (e.g., Hirshleifer and Thakor, 1994 and 1998). To take into account the potential impact of takeover defense provisions, in this section we create dummy variables for four antitakeover provisions used in Ferreira, Ferreira, and Raposo (2011) in our estimation. These are: poison pill (PPILL), staggered (or classified) board $(C B O A R D)$, cumulative voting (CUMVOTE), and supermajority vote requirements (SUPERMAJOR). Column 1 of Table $9^{45}$ shows the coefficient on PPILL is significantly positive at the $1 \%$ level, suggesting that the board is more independent if the firm has the poison pill provision in place (such positive association between antitakeover provisions and board independence is also documented by Danielson and Karpoff, 1998, and Borokhovich, Brunarski, and Parrino, 1997). Or, equivalently, the board is less independent if the firm is open to a takeover threat. The implication is that board independence and takeover threat are likely to be substitutes. ${ }^{46} \mathrm{We}$ do not,

\footnotetext{
45 The number of observations decreases considerably because the report of takeover defense by RiskMetrics is only available for the following years within the observation period (1996-2007): 1998, 2000, 2002, 2004, and 2006.

${ }^{46}$ Alternatively, while antitakeover provisions enable managers to expropriate shareholder wealth, they may also benefit shareholders in some way by increasing the bargaining power of the CEO in the negotiation with the bidders, as posited by Borokhovich et al. (1997).
} 
however, find other antitakeover provisions to be associated with board independence. More importantly, despite the significant association between the poison pill provision and board independence, our key findings remain unchanged — the coefficient on Swing is still positive and significant (at the $10 \%$ level). We also re-estimate the regression using alternative measures to Swing. The results still hold, as reported in Column 2 (using Ln_Num_Mgr) and Column 3 (using Turnover_TRA) of Table 9.

$$
<<\text { Insert Table 9>> }
$$

\subsection{Alternative measure for effectiveness of board monitoring: CEO turnover}

A major concern about using Board Independence as a dependent variable is it does not change very much from year to year. In addition, one can also argue that the proportion of independent directors says little about the real action or decision taken by the board. To address these issues, we replace Board Independence in regression model (11) with CEO turnover (a dummy variable, set to 1 if CEO is replaced in that year and 0 otherwise) as the dependent variable and then examine whether Swing leads to a higher likelihood of CEO turnover as a result of more effective board monitoring. Recent papers have found that CEO turnover is more likely when board monitoring becomes more effective, due to either a more independent board (e.g., Guo, 2010) or the pressure from shareholders (e.g., Cai et al., 2009). ${ }^{47}$

Using a logistic analysis to estimate whether the probability of CEO turnover is related to institutional investor monitoring, we find that the more informative stock prices become due to WSR, the higher the likelihood of CEO turnover is - the coefficient on Swing is positive and significant at the $10 \%$ level (unreported here but available upon request). These results provide direct evidence that WSR indeed has a

\footnotetext{
${ }^{47}$ Another potential outcome of more effective board monitoring is that CEO compensation may come under closer scrutiny. Indeed, CS find that aggressive institutional trading due to WSR leads to lower managerial equity allocation.
} 
real impact on a CEO's career prospect via more effective board monitoring. It also complements the results reported by Cai et al. (2009) that CEO turnover is more likely when independent directors receive fewer votes from shareholders (in an environment where the vast majority of directors receive high votes). Namely, independent directors play a key role in determining CEO turnover, especially when they become more informed about CEO action due to WSR (as this study shows) or when they are under pressure from shareholders (Cai et al., 2009). ${ }^{48}$

\section{Conclusion}

In this study, we examine the relation between a form of institutional investor monitoring - the Wall Street Rule (WSR) - and an internal governing mechanism, board monitoring. We show that board monitoring (proxied by board independence) becomes more effective when the informational environment improves as informed traders impound more information in stock prices by trading aggressively. This finding suggests that stock prices indeed serve as a valid source of information about managerial action for board members. However, such positive association between WSR and board monitoring occurs only when the firm is endowed with a board dominated by outsiders in the first place. That is, the initial condition of board monitoring matters. If a firm starts with an insider-dominated board, then improving price informativeness would not increase board monitoring much.

Our results are robust to the pre-SOX and post-SOX periods, the inclusion of firm fixed effects, and several alternative measures. They also hold after taking into account endogeneity. More broadly, this study illustrates an active role of price efficiency in corporate finance research: institutional investors' pure pursuit of trading profits not

\footnotetext{
${ }^{48}$ Cai et al. (2009) do not find that votes on the inside directors have any effect on CEO turnover.
} 
only helps spur the CEO to work harder, as suggested by the recent literature, but also enables board members to monitor the CEO more effectively on behalf of shareholders. 


\section{Appendix}

\section{Proof of Proposition 1}

Firstly let $\tilde{v}^{*}=\tilde{v}-\omega$. Following Kyle (1985), EM and CS, the $i$ th of $N$ informed trader adopts a linear strategy, $x_{i}(\tilde{s})=\kappa+\gamma \tilde{s}$ where $\kappa$ is some constant and $\gamma$ denotes trade aggressiveness. $\tilde{s}$ represents the imperfect signal (biased upwardly due to managerial manipulation) observed by informed traders.

A competitive market maker observing the aggregate informed plus uninformed order flow, $z$, also has a linear pricing rule, $\hat{p}(z)=p_{0}+\lambda z$, where $p_{0}$ stands for some constant.

The $i$ th symmetric informed trader chooses $x_{i}$ to maximize his expected profits, $E\left[\left(\tilde{v}_{i}^{*}-p_{0}-\lambda z\right) x_{i} \mid \tilde{s}_{i}=s\right]=\left\{h+\frac{\sigma_{\eta}^{2}}{\sigma_{\eta}^{2}+\sigma_{\varepsilon}^{2}}[\tilde{s}-E(\tilde{s})]-\frac{\lambda(N-1) \gamma \sigma_{\eta}^{2}}{\sigma_{\eta}^{2}+\sigma_{\varepsilon}^{2}}[\tilde{s}-E(\tilde{s})]\right\} x_{i}-\lambda x_{i}^{2}$,

where $h=(1-\lambda(N-1) \gamma) \phi_{a} a^{e}-(1+\lambda(N-1) \gamma) w^{e}-p_{0}-\lambda(N-1) \kappa$.

The first order condition with respect to $x_{i}$ yields:

$x_{i}(\tilde{s})=\frac{h}{2 \lambda}-\frac{1}{2}\left(\frac{1}{\lambda}-(N-1) \gamma\right) \frac{\sigma_{\eta}^{2}}{\sigma_{\eta}^{2}+\sigma_{\varepsilon}^{2}} E(\tilde{s})+\frac{1}{2}\left(\frac{1}{\lambda}-(N-1) \gamma\right) \frac{\sigma_{\eta}^{2}}{\sigma_{\eta}^{2}+\sigma_{\varepsilon}^{2}} \tilde{s}$.

The $N-1$ terms involving $\gamma$ take account of the responses of the other players in the Nash equilibrium. By comparing the first order condition with respect to $x_{i}$ with the informed trader's linear trading strategy, we obtain: $\gamma=\frac{\sigma_{\eta}^{2}}{\left[\sigma_{\eta}^{2}(N+1)+2 \sigma_{\varepsilon}^{2}\right] \lambda}$.

The market maker sets the price based upon the total order flow he observes: $p(z)=E\left(\tilde{v}^{*} \mid z\right)$, where the total order flow is $\mathrm{z}=\sum_{i} x_{i}+u=N(\kappa+\gamma \tilde{s})+u$.

Since both $\tilde{v}^{*}$ and $Z$ follow normal distribution, we can show:

$$
p(z)=E\left(\tilde{v}^{*} \mid z\right)=E\left(\tilde{v}^{*}\right)+\frac{\operatorname{Cov}\left(\tilde{v}^{*}, z\right)}{\operatorname{var}(z)}(z-E(z)) .
$$

It follows that Kyle's lambda has the form: $\lambda=\frac{\operatorname{Cov}\left(\tilde{v}^{*}, z\right)}{\operatorname{var}(z)}=\frac{\sqrt{N\left(\sigma_{\eta}^{2}+\sigma_{\varepsilon}^{2}\right)} \sigma_{\eta}^{2}}{\sigma_{u}\left[(N+1) \sigma_{\eta}^{2}+2 \sigma_{\varepsilon}^{2}\right]}$, by incorporating $\gamma$.

Solving for $\mu$ and $\kappa$ yields: 


$$
\begin{aligned}
& \mu=\phi_{a} a^{e}-\omega^{e} \\
& \kappa=-\gamma \phi_{a} a^{e}-\gamma \omega^{e} .
\end{aligned}
$$

We then obtain the following expression for the normalized price $\hat{p}(z)$ :

$$
\begin{aligned}
p(z) & =\left(\phi_{a} a^{e}-\omega^{e}\right)+\lambda[N(\kappa+\gamma \tilde{s})+u] \\
& =\left(\phi_{a} a^{e}-\omega^{e}\right)-\beta\left(\phi_{a} a^{e}+\omega^{e}\right)+\beta \tilde{s}+\lambda u \\
& =\left(\phi_{a} a^{e}-\omega^{e}\right)-\beta\left(\phi_{a} a^{e}+\omega^{e}\right)+\beta(\tilde{v}+\tilde{\varepsilon}+\omega)+\lambda u .
\end{aligned}
$$

As per EM's definition of price informativeness, $E\left[\frac{d \hat{p}}{d v}\right]$, we establish

$$
E\left[\frac{d \hat{p}}{d v}\right]=\frac{\phi \sigma_{\eta}^{2}}{\sigma_{\eta}^{2}+2(1-\phi) \sigma_{\varepsilon}^{2}} \equiv \beta
$$

where $\phi \equiv \frac{N}{N+1}$. Q.E.D.

\section{Some comments on Proposition 3:}

The condition for $\frac{d g}{d \beta}>0(<0)$ is when the product of the numerator and denominator to becomes positive (negative). The composition of the product expression is as follows:

Product $=$

$(-G K) \rho^{4}+\left(G H+\frac{1}{4} g^{2} E B K\right) \rho^{3}+\left(G I-\frac{1}{4} g^{2} E B H+K J\right) \rho^{2}+\left(-J H-\frac{1}{4} g^{2} E B I\right) \rho-J I$

where

$$
\begin{aligned}
G & =\frac{1}{8} \beta^{3} g^{4} A(g-1)^{2}-\frac{1}{4} \hat{\alpha}_{\hat{p}} \beta^{3} g^{2} A\left(2 \hat{\alpha}_{\hat{p}} \beta+3\right) B \\
H & =\frac{1}{4} L \hat{\alpha}_{\hat{p}} \beta^{4} D+\frac{1}{4} \beta^{3} \phi g^{3}(g-1)^{3}+\frac{1}{4} L \hat{\alpha}_{\hat{p}}^{2} \beta^{5} g C-\frac{1}{8} L \beta^{4} g^{4}\left(\frac{1}{2} \beta+2\right)(g-1) \\
I & =\beta \phi+\frac{1}{2} \beta^{2} \phi g^{2}+\frac{1}{4} \beta^{3} \phi g^{3}+g(g-1)\left(4 \beta \phi+\hat{\alpha}_{\hat{p}} \beta^{2} \phi\left(\hat{\alpha}_{\hat{p}} \beta+2\right)\right)-\frac{1}{2} \hat{\alpha}_{\hat{p}} \beta^{3} \phi g^{2}(2 g-1) \\
J & =\phi g F+\frac{1}{2} \beta \phi g^{3}(g-2)-\frac{1}{8} \beta^{3} \phi \phi_{a}^{2} g^{4}(g-1)^{2} \\
K & =\frac{1}{16} L \beta^{5} g^{4}(g-1)^{4} \\
E & =\beta^{2} \phi \phi_{a}^{2}\left(3 \hat{\alpha}_{\hat{p}} \beta-1\right)+\hat{\alpha}_{\hat{p}} \beta^{3} \phi \phi_{a}^{2}\left(2 \hat{\alpha}_{\hat{p}} \beta-1\right) \\
B & =2 g^{3}-5 g^{2}+4 g-1
\end{aligned}
$$


and

$L=\phi \phi_{a}^{2}+\rho A$

$A=\sigma_{\varepsilon}^{2}+\sigma_{\eta}^{2}$

$C=3 g^{3}-6 g^{2}+4 g-1$

$D=g^{3}(6 g-12)+g(8 g-2)$

$F=2 g^{2}-3 g+1$

Finally, also note that $\phi=\frac{N}{N+1}$.

By varying $g$ from 0.1 to 1 , we get the result as shown in Proposition 3 . This result is robust to varying values of other parameters in the product expression. 


\section{References}

Adams, R., Ferreira, D., 2007. A theory of friendly boards. Journal of Finance 62, 217250.

Adams, R., Hermalin, B., Weisbach, M., 2010. The role of boards of directors in corporate governance: a conceptual framework and survey. Journal of Economic Literature 48, 58-107.

Admati, A., Pfleiderer, P., 2009. The "Wall Street Walk" and shareholder activism: exit as a form of voice. Review of Financial Studies 22, 2645-2685

Admati, A., Pfleiderer, P. Zechner, J., 1994. Large shareholder activism, risk sharing, and financial market equilibrium. Journal of Political Economy 102, 1097-1130.

Aktas, N., de Bodt, E., Declerck, F., Van Oppens, H., 2007. The PIN anomaly around M\&A announcements. Journal of Financial Markets 10, 169-191.

Aslan, H., Easley, D., Hvidkjaer, S., O’Hara, M., 2011. Firm characteristics and informed trading: implications for asset pricing. Journal of Empirical Finance 18, 782801.

Beasley, M., 1996. An empirical analysis of the relation between the board of director composition and financial statement fraud. The Accounting Review 71, 443-465.

Becker, G., 1968. Crime and punishment: an economic approach. Journal of Political Economy 76, 169-217.

Bennett, J., Sias, R., Starks, L., 2003. Greener pastures and the impact of dynamic institutional preferences. Review of Financial Studies 16, 1203-38.

Bergstresser, D., Philippon, T., 2006. CEO incentives and earnings management. Journal of Financial Economics 80, 511-529. 
Boehmer, E., Kelley, E., 2009. Institutional investors and the informational efficiency of prices. Review of Financial Studies 22, 3563-3594.

Boone, A., Field, L., Karpoff, J., Raheja, C., 2007. The determinants of corporate board size and composition: an empirical analysis. Journal of Financial Economics 85, 66101.

Booth, J., and Deli, D., 1999. On executives of financial institutions as outside directors. Journal of Corporate Finance 5, 221-250.

Borokhovich, K., Brunarski, K., Parrino, R., 1997. CEO contracting and antitakeover amendments. Journal of Finance 52, 1495-1517.

Burns, N., and Kedia, S., 2006. The impact of performance-based compensation on misreporting. Journal of Financial Economics 79, 35-67.

Bushee, B., 1998. The influence of institutional investors on myopic R\&D investment behavior. The Accounting Review 73, 305-333.

Bushee, B., 2001. Do institutional investors prefer near-term earnings over long-run value? Contemporary Accounting Review 18, 207-246.

Cai, J., Garner, J., Walkling, R., 2009. Electing directors. Journal of Finance 64, 23892421.

Chen, B., Swan, P., 2010. CEO incentives and institutional trader monitoring are substitutes: theory and evidence. Unpublished working paper. University of New South Wales, Australia.

Chen, X., Harford, J., Li, K., 2007. Monitoring: which institutions matter? Journal of Financial Economics 86, 279-305. 
Chhaochharia, V., Grinstein, Y., 2009. CEO compensation and board structure. Journal of Finance 64, 231-261.

Coles, J., Daniel, N., Naveen, L., 2008a. Boards: does one size fit all? Journal of Financial Economics 87, 329-356.

Coles, J., Lemmon, M., Wang, Y., 2008b. The joint determinants of managerial ownership, board independence, and firm performance. Unpublished working paper. Arizona State University.

Core, J., Guay, W., and Rusticus, T., 2006. Does weak governance cause weak stock returns? an examination of firm operating performance and investors' expectations. Journal of Finance 61, 655-687.

Dahya, J., Dimitrov, O., McConnell, J., 2007. Dominant shareholders, corporate boards, and corporate value: a cross-country analysis. Journal of Financial Economics $87,73-100$.

Daniel, K., Grinblatt, M., Titman, S., Wermers, R., 1997, Measuring mutual fund performance with characteristic-based benchmarks, Journal of Finance 52, 1035-1058.

Danielson, M., Karpoff, J., 1998. On the uses of corporate governance provisions. Journal of Corporate Finance 4, 347-371.

Davidson, R., MacKinnon, J., 1993. Estimation and Inference in Econometrics. Oxford University Press, New York.

Demsetz, H., Lehn, K., 1985. The structure of corporate ownership: causes and consequences. Journal of Political Economy 93, 1155-1177.

Dow, J., Gorton, G., 1997. Stock market efficiency and economic efficiency: is there a connection? Journal of Finance 52, 1087-1129. 
Duarte, J., Young, L., 2009. Why is PIN priced? Journal of Financial Economics 91, $119-138$

Duchin, R., Matsusaka, J., Ozbas, O., 2010. When are outside directors effective? Journal of Financial Economics 96, 195-214.

Easley, D., Hvidkjaer, S., O’Hara, M., 2002. Is information risk a determinant of asset returns? Journal of Finance 57, 2185-2221.

Edmans, A., Fang, V., Zur, E., 2011. The effect of liquidity on governance. Unpublished working paper.

Edmans, A., Manso, G., 2011. Governance through trading and intervention: a theory of multiple blockholders. Review of Financial Studies 27, 2395-2428.

Fama, E., Jensen, M., 1983. Separation of ownership and control. Journal of Law and Economics 26, 306-326.

Faure-Grimaud, A., Gromb, D., 2004. Public trading and private incentives. Review of Financial Studies 17, 985-1014.

Ferreira, D., Ferreira, M., Raposo, C., 2011. Board structure and price informativeness. Journal of Financial Economics 99, 523-545.

Fich, E., Shivdasani, A., 2007. Financial fraud, director reputation, and shareholder wealth. Journal of Financial Economics 86, 306-336.

Gallagher, D., Gardner, P., Swan, P., 2013. Governance through trading: Institutional swing trades and subsequent firm performance. Journal of Financial and Quantitative Analysis 48, 427-458 . 
Gaver, J., Gaver, K., 1993. Additional evidence on the association between the investment opportunity set and corporate financing, dividend, and compensation policies. Journal of Financial Economics 16, 125-160.

Gillan, S., Hartzell, J., Starks, L., 2011. Tradeoffs in corporate governance: evidence from board structures and charter provisions. Quarterly Journal of Finance 1, 667-705

Gilson, S., 1990. Bankruptcy, boards, banks and blockholders: evidence on changes in corporate ownership and control when firms default. Journal of Financial Economics $27,355-387$.

Goldman, E., Slezak, S., 2006. An equilibrium model of incentive contracts in the presence of information manipulation. Journal of Financial Economics 80, 603-626.

Gopalan, Radhakrishnan, 2008, Institutional stock sales and takeovers: the disciplinary role of voting with your feet. Unpublished working paper. Washington University, St. Louis.

Gompers, P., Metrick, A., 2001. Institutional investors and equity prices. Quarterly Journal of Economics 116, 229-259.

Gordon, J., 2007. Independent directors and stock market prices: the new corporate governance paradigm. Stanford Law Review 59, 1465-1568.

Guo, L., 2010. Board structure and monitoring: new evidence from CEO turnover. Unpublished working Paper. University of New South Wales.

Guthrie, K., Sokolowsky, J., Wan, K., 2010. CEO compensation and board structure revisited. Journal of Finance, forthcoming. 
Harris, M., Raviv, A., 2008. A theory of board control and size. Review of Financial Studies 21, 1797-1832.

Haubrich, J., 1994. Risk aversion, performance pay, and the principal-agent problem. Journal of Political Economy 102, 258-276.

Helwege, J., Intintoli, V., Zhang, A., - 2012. Voting with their feet or activism? institutional investors' impact on CEO turnover. Journal of Corporate Finance 18, 2237.

Hermalin, B., Weisbach, M., 1988. The determinant of board composition. RAND Journal of Economics 19, 489-606.

Hermalin, B.,. Weisbach, M., 1998. Endogenously chosen boards of directors and their monitoring of the CEO. American Economic Review 88, 96-118.

Hermalin, B., Weisbach, M., 2003. Boards of directors as an endogenously determined institution: a survey of the economic literature. Economic Policy Review 9, 7-26.

Hermalin, B., Weisbach, M., 2009. Information disclosure and corporate governance. Journal of Finance, forthcoming.

Himmelberg, C., Hubbard, G., Palia, D., 1999, Understanding the determinants of managerial ownership and the link between ownership and performance. Journal of Financial Economics 53, 353-384.

Hirshleifer, D., Thakor, A., 1994. Managerial performance, boards of directors and takeover bidding. Journal of Corporate Finance 1, 63-90.

Hirshleifer, D., Thakor, A., 1998. Corporate control through board dismissals and takeovers. Journal of Economics and Management Strategy 7, 489-520. 
Holmstrom, B., Tirole, J., 1993. Market liquidity and performance monitoring. Journal of Political Economy 101, 678-709.

Jensen, M., 1986. Agency costs of free cash flow, corporate finance, and takeovers. American Economic Review 76, 323-329.

Jensen, M., 1989. Eclipse of the public corporation. Harvard Business Review 67, 6174.

Kahn, C., Winton, A., 1998. Ownership structure, speculation, and shareholder intervention. Journal of Finance 53, 99-129.

Kaplan, S., Reishus, D., 1990. Outside directorships and corporate performance. Journal of Financial Economics 27, 389-410.

Kaplan, S., Minton, B., 2012. How has CEO turnover changed? International Review of Finance 12, 57-87.

Klein, A., 1998. Firm performance and board committee structure. Journal of Law and Economics 41, 275-302.

Klein, A., 2002, Audit committee, board of director characteristics, and earnings management. Journal of Accounting and Economics 33, 375-400.

Kyle, A., 1985. Continuous auctions and insider trading. Econometrica 53, 1315-1336. Lehn, K., Patro, S., Zhao, M., 2009 . Determinants of the size and structure of corporate boards: 1935-2000. Financial Management 38, 747-780.

Linck, J., Netter, J., Yang, T., 2008. The determinants of board structure. Journal of Financial Economics 87, 308-328. 
Linck, J., Netter, J., Yang, T., 2009. The effects and unintended consequences of the Sarbanes-Oxley Act on the supply and demand for directors. Review of Financial Studies 22, 3287-3328.

Mace, M., 1971. Directors: Myth and Reality. Harvard Business Press, Boston.

Maug, E., 1997. Boards of directors and capital structure: alternative forms of corporate restructuring. Journal of Corporate Finance 3, 113-139.

Maug, E., 1998. Large shareholders as monitors: is there a tradeoff between liquidity and control? Journal of Finance 53, 65-98.

Noe, T., 2002. Investor activism and financial market structure. Review of Financial Studies 15, 289-318.

Norli, Ø., Ostergaard, C. Schindele, I., 2010. Liquidity and shareholder activism. Unpublished working paper. Norwegian School of Management.

Parrino, R., Sias, R., Starks, L., 2003. Voting with their feet: institutional ownership changes around forced CEO turnover. Journal of Financial Economics 68, 3-46.

Petersen, M., 2009. Estimating standard errors in finance panel data sets: comparing approaches. Review of Financial Studies 22, 435-480.

Rahejia, C., 2005. Determinants of board size and composition: a theory of corporate boards. Journal of Financial and Quantitative Analysis 40, 283-306.

Rajgopal, S., Shevlin, T., 2002. Empirical evidence on the relation between stock option compensation and risk taking, Journal of Accounting and Economics 33, 145-171.

Sargan, J., 1958. The estimation of economic relationships using instrumental variables. Econometrica 26, 393-415. 
Sias, R., Starks, L., Titman, S., 2006. Changes in institutional ownership and stock returns: assessment and methodology. Journal of Business 79, 2869-2910.

Shleifer, A., Vishny, R., 1986. Large shareholders and corporate control. Journal of Political Economy 98, 461-488.

Smith, C., Watts, R., 1992. The investment opportunity set and corporate financing, dividend, and compensation policies. Journal of Financial Economics 32, 263-292.

Smith, G., Swan, P., 2008. Will the real monitor please stand up? Institutional investors and CEO compensation, Unpublished working paper. University of New South Wales.

Weisbach, M., 1988. Outside directors and CEO turnover. Journal of Financial Economics 4, 53-70.

Wintoki, B., Linck, J., Netter, J., 2012 . Endogeneity and the dynamics of internal corporate governance. Journal of Financial Economics 105, 581-606 .

Xie, B., Davidson, W., III, DaDalt, P., 2003. Earnings management and corporate governance: the roles of the board and the audit committee. Journal of Corporate Finance 9, 295-316.

Yan, X. Zhang, Z., 2009. Institutional investors and equity returns: are short-term institutions better informed? Review of Financial Studies 22, 893-924.

Yermack, D., 1996. Higher market valuation of companies with a small board of directors. Journal of Financial Economics 40, 185-213.

Yermack, D., 2004, Remuneration, retention, and reputation incentives for outside Directors. Journal of Finance 59, 2281-2308. 
Table 1: Variable definitions

\begin{tabular}{|c|c|}
\hline Variables & Definition \\
\hline Board independence & Number of independent directors scaled by the board size from 1996 to 2007 (sourced from RiskMetrics). \\
\hline Board size & Number of directors on the board from 1996 to 2007 (sourced from RiskMetrics). \\
\hline $\begin{array}{l}\text { Turnover(Trading_pattern) } \\
\text { and Swing }\end{array}$ & $\begin{array}{l}\text { The annual sum of the absolute value of quarterly changes in institutional holdings, aggregated across all } \\
\text { institutions investors who engage in a particular "trading pattern" in the firm, scaled by the total number of shares } \\
\text { outstanding. The "trading pattern" is identified by the changes in institutional shareholdings for four conseutive } \\
\text { quarters from December (t-1) to September ( } \mathrm{t} \text { ). The turnover of institutional investors engaging in the trading } \\
\text { pattern of "Buy-Sell-Buy" is termed "Swing" trading in this study (sourced from Thomson 13f filling database). }\end{array}$ \\
\hline Top5_Shrout & The five largest institutional investors' ownership of the firm, sourced from Thomson $13 \mathrm{f}$ filing database. \\
\hline Sales (real, \$M) & Net sales as reported in Comupstat, expressed in \$ millions. The price is in 2006 dollars. \\
\hline Debt_Ratio & The ratio of book value of total liabilities to book value of total assets (Compustat). \\
\hline NumSegments & Number of business segments of a frim (Compustat). \\
\hline FirmAge & Number of months since the firm first appeared on CRSP. \\
\hline Market-to-book (adjusted) & $\begin{array}{l}\text { The book-to-market ratio is computed first by dividing the book value for the fiscal year ended before the } \\
\text { most recent June } 30 \text { by market capitalization of December } 31 \text { during that fiscal year. This ratio is then adjusted } \\
\text { for long-term industry average following Daniel et al. (1997). The adjusted Market-to-book ratio is computed by } \\
\text { taking the reciprocal of the adjusted Book-to-market ratio (CRSP/Compustat). }\end{array}$ \\
\hline $\mathrm{R} \& \mathrm{D} / \mathrm{A}$ & The ratio of research and development expenditures to book value of total assets (Compustat). \\
\hline Lag_Ret_Volat & Annualized standard deviation of monthly stock returns over the 12 months in the previous year (CRSP). \\
\hline PPS_Total & $\begin{array}{l}\text { The dollar value change in the CEO's total equity-based compensation (including both share and option holdings) } \\
\text { per } \$ 1000 \text { change in shareholder value. It is calculated by dividing the sum of share equivalent of the CEO's } \\
\text { option holdings and the CEO's shareholdings by the total number of shares outstanding at the beginning of the } \\
\text { fiscal year. The share equivalent of the CEO's option holdings is the product of the number of option granted } \\
\text { and the hedge ratio, based on the Black-Scholes formula adjusted for dividends. (ExecuComp). }\end{array}$ \\
\hline FCF (Free cash flow) & $\begin{array}{l}\text { Free cash flow is calculated by scaling operating income before depreciation minus capital expenditure by total } \\
\text { assets, following Boone et al. (2007). Data is sourced from Compustat. }\end{array}$ \\
\hline Industry Herfindahl & $\begin{array}{l}\text { Industry Herfindahl index, calculated as the sum of squared market shares of firm's sales in the industry, using } \\
\text { 2-digit SIC codes (Compustat). }\end{array}$ \\
\hline CEO_tenure & Number of years since the CEO has been CEO with the firm (ExecuComp). \\
\hline Lag_ROA & $\begin{array}{l}\text { Return on assets in the previous year, computed as the ratio of income before extraordinary items to book value } \\
\text { of total assets (Compustat). }\end{array}$ \\
\hline
\end{tabular}




\section{Table 2: Descriptive statistics (1996-2007)}

The table contains time-series and cross-sectional statistics of main variables in this study from 1996 to 2007. The sample consists of ExecuComp/RiskMetrics firms from 1996 to 2007 but firms in the financial and highly regulated industries (two-digit SIC code $=49,60-69$ ) are excluded. The variables are defined in Table 1.

\begin{tabular}{|c|c|c|c|c|c|c|c|c|}
\hline Variables & Obs. & Mean & Std Dev & Min & $25 \%$ ile & Median & $75 \%$ ile & Max \\
\hline \multicolumn{9}{|c|}{ Panel A: Board Independence and Size } \\
\hline Board independence & 7752 & $66.26 \%$ & $17.07 \%$ & $20.00 \%$ & $55.56 \%$ & $66.67 \%$ & $80.00 \%$ & $91.67 \%$ \\
\hline Board size & 7752 & 9.310 & 2.520 & 3 & 7 & 9 & 11 & 26 \\
\hline \multicolumn{9}{|c|}{ Panel B: Ins titutional Trading and Concentration Variables } \\
\hline Turnover(Buy-Sell-Buy) & 7430 & $2.40 \%$ & $2.33 \%$ & $0.02 \%$ & $0.75 \%$ & $1.69 \%$ & $3.27 \%$ & $11.41 \%$ \\
\hline Turnover(Sell-Buy-Sell) & 7150 & $2.37 \%$ & $2.34 \%$ & $0.01 \%$ & $0.68 \%$ & $1.66 \%$ & $3.27 \%$ & $11.53 \%$ \\
\hline Turnover(Sell-Buy) & 5778 & $0.16 \%$ & $0.33 \%$ & $0.00 \%$ & $0.01 \%$ & $0.04 \%$ & $0.14 \%$ & $2.31 \%$ \\
\hline Turnover(Buy-Sell) & 6553 & $0.30 \%$ & $0.60 \%$ & $0.00 \%$ & $0.02 \%$ & $0.08 \%$ & $0.27 \%$ & $3.60 \%$ \\
\hline Turnover(Buy-Buy-Buy) & 7651 & $4.97 \%$ & $3.65 \%$ & $0.05 \%$ & $2.21 \%$ & $4.15 \%$ & $6.87 \%$ & $16.50 \%$ \\
\hline Turnover(Sell-Sell-Sell) & 7573 & $3.96 \%$ & $3.16 \%$ & $0.02 \%$ & $1.56 \%$ & $3.17 \%$ & $5.60 \%$ & $14.11 \%$ \\
\hline Turnover(Other patttern) & 7747 & $13.42 \%$ & $7.92 \%$ & $0.47 \%$ & $7.51 \%$ & $12.19 \%$ & $17.96 \%$ & $36.10 \%$ \\
\hline InstTrade & 7752 & $27.17 \%$ & $13.23 \%$ & $1.40 \%$ & $17.33 \%$ & $25.96 \%$ & $35.75 \%$ & $60.70 \%$ \\
\hline Top5_Shrout & 7752 & $26.70 \%$ & $8.74 \%$ & $6.05 \%$ & $20.48 \%$ & $26.23 \%$ & $32.46 \%$ & $51.12 \%$ \\
\hline \multicolumn{9}{|c|}{ Panel C: Scope of Operation Hypothes is } \\
\hline Sales (real, \$M) & 7751 & 5632.94 & 11018.29 & 28.09 & 657.99 & 1667.61 & 4974.03 & 67652.32 \\
\hline Debt_Ratio & 7734 & 0.22 & 0.16 & 0.00 & 0.09 & 0.22 & 0.33 & 0.83 \\
\hline Number of business segments & 7675 & 2.74 & 1.75 & 1 & 1 & 3 & 4 & 10 \\
\hline FirmAge (in months) & 7752 & 307.77 & 244.22 & 11 & 119 & 231 & 412 & 982 \\
\hline \multicolumn{9}{|c|}{ Panel D: Monitoring Hypothesis } \\
\hline Market-to-book (adjusted) & 7752 & -2.06 & 20.63 & -96.37 & -5.90 & -2.46 & 2.47 & 91.18 \\
\hline $\mathrm{R} \& \mathrm{D} / \mathrm{A}$ & 7752 & 0.031 & 0.051 & 0.000 & 0.000 & 0.006 & 0.041 & 0.282 \\
\hline Lag_Ret_Volat & 7512 & 0.42 & 0.20 & 0.13 & 0.28 & 0.37 & 0.50 & 1.19 \\
\hline PPS_Total & 7752 & 35.33 & 58.77 & 0.15 & 6.70 & 14.86 & 33.90 & 346.00 \\
\hline FCF & 7677 & 0.083 & 0.092 & -0.355 & 0.044 & 0.086 & 0.131 & 0.341 \\
\hline Industry Herfindahl & 7752 & 0.16 & 0.14 & 0.04 & 0.08 & 0.11 & 0.19 & 1.00 \\
\hline \multicolumn{9}{|c|}{ Panel E: Negotiation Hypothesis } \\
\hline CEO_tenure & 7359 & 7.19 & 7.18 & 0 & 2 & 5 & 10 & 35 \\
\hline Lag_ROA & 7240 & 0.048 & 0.085 & -0.502 & 0.023 & 0.055 & 0.089 & 0.234 \\
\hline
\end{tabular}


Table 3: Comparison of compliant and non-compliant firms pre-SOX (before 2000)

This table compares the characteristics of compliant firms with those of non-compliant ones in 1996, 1998, and 2000, respectively. Compliant firms are defined as the firms with a board comprising more than $50 \%$ of independent directors; non-compliant firms are those that are not compliant firms. \%IndepDir represents the proportion of independent directors on the board and all the other variables are defined in Table 1. We test the difference between the two comparing samples and report t-statistics for each variable. The asterisks indicate statistical significance at the $1 \%(* * *), 5 \%(* *)$, and $10 \%(*)$ levels.

\begin{tabular}{|c|c|c|c|c|c|c|c|c|c|c|c|c|c|c|c|}
\hline & \multicolumn{5}{|c|}{1996} & \multicolumn{5}{|c|}{1998} & \multicolumn{5}{|c|}{2000} \\
\hline & \multicolumn{2}{|c|}{$\begin{array}{l}\text { Compliant firms } \\
\end{array}$} & \multicolumn{2}{|c|}{ Noncompliant firms } & \multirow{2}{*}{$\begin{array}{l}\text { t-statistic for } \\
\text { differnce }\end{array}$} & \multicolumn{2}{|c|}{ Compliant firms } & \multicolumn{2}{|c|}{ Noncompliant firms } & \multirow{2}{*}{$\begin{array}{l}\text { t-statistic for } \\
\text { differnce }\end{array}$} & \multicolumn{2}{|c|}{ Compliant firms } & \multicolumn{2}{|c|}{ Noncompliant firms } & \multirow{2}{*}{$\begin{array}{l}\text { t-statistic for } \\
\text { differnce }\end{array}$} \\
\hline & Mean & Std Dev & Mean & Std Dev & & Mean & Std Dev & Mean & $\overline{\text { Std Dev }}$ & & Mean & Std Dev & Mean & $\overline{\text { Std Dev }}$ & \\
\hline$\%$ Indep Dir & 68.64 & 11.53 & 35.12 & 8.67 & $34.00 * * *$ & 68.59 & 11.96 & 34.78 & 8.82 & $39.10^{* * * *}$ & 70.15 & 12.20 & 35.48 & 8.16 & $39.32 * * *$ \\
\hline Swing & $2.02 \%$ & $2.10 \%$ & $1.75 \%$ & $2.30 \%$ & 1.06 & $2.17 \%$ & $2.04 \%$ & $1.83 \%$ & $2.15 \%$ & $1.76^{*}$ & $1.74 \%$ & $1.87 \%$ & $1.67 \%$ & $1.89 \%$ & 0.4 \\
\hline Sales & 7243.67 & 12577.41 & 3363.97 & 5154.52 & $4.92 * * *$ & 5966.56 & 11089.74 & 2809.33 & 6788.46 & $4.40^{* * * *}$ & 6046.98 & 11463.35 & 3464.03 & 8177.68 & $2.99 * * *$ \\
\hline Debt_Ratio & 0.24 & 0.14 & 0.24 & 0.18 & -0.09 & 0.25 & 0.16 & 0.25 & 0.20 & -0.1 & 0.25 & 0.16 & 0.24 & 0.19 & 0.55 \\
\hline Num_segment & 2.26 & 1.48 & 1.77 & 1.19 & $3.68 * * *$ & 2.70 & 1.65 & 2.01 & 1.49 & $5.00^{\text {**** }}$ & 3.01 & 1.78 & 2.41 & 1.79 & $3.48 * * *$ \\
\hline FirmAge (months) & 395.49 & 253.67 & 252.40 & 179.40 & $6.87^{* * * *}$ & 323.31 & 256.24 & 206.31 & 165.42 & $6.84^{* * * *}$ & 322.00 & 255.72 & 183.08 & 149.46 & $8.16 * * *$ \\
\hline Market-to-book & -2.45 & 16.55 & 0.48 & 19.54 & -1.48 & -2.89 & 17.10 & -2.37 & 18.90 & -0.31 & -2.07 & 18.54 & -1.33 & 20.93 & -0.37 \\
\hline$R \& D / A$ & 0.03 & 0.04 & 0.03 & 0.05 & -0.7 & 0.04 & 0.06 & 0.03 & 0.06 & 1.33 & 0.03 & 0.05 & 0.02 & 0.04 & $2.63^{* *}$ \\
\hline Ret_Volat & 0.30 & 0.12 & 0.38 & 0.18 & $-4.24 * * *$ & 0.42 & 0.16 & 0.45 & 0.15 & $-2.32^{* * *}$ & 0.56 & 0.22 & 0.59 & 0.20 & -1.47 \\
\hline FCF & 0.09 & 0.08 & 0.07 & 0.10 & $1.72^{*}$ & 0.08 & 0.10 & 0.06 & 0.12 & $2.05 * *$ & 0.09 & 0.09 & 0.08 & 0.09 & 1.31 \\
\hline Industry Herfindahl & 0.16 & 0.15 & 0.17 & 0.13 & -0.64 & 0.15 & 0.13 & 0.17 & 0.14 & $-1.96^{*}$ & 0.16 & 0.14 & 0.19 & 0.16 & -1.63 \\
\hline PPS_Total & 22.37 & 42.68 & 57.34 & 81.49 & $-4.48^{* * * *}$ & 27.01 & 47.44 & 60.49 & 83.31 & $-4.90 * * *$ & 31.01 & 51.91 & 73.68 & 93.62 & $-5.07 * * *$ \\
\hline ROA & 0.06 & 0.06 & 0.05 & 0.08 & 1.49 & 0.04 & 0.09 & 0.04 & 0.09 & 0.90 & 0.05 & 0.09 & 0.05 & 0.08 & 0.41 \\
\hline CEOTenure & 6.38 & 6.59 & 9.50 & 8.24 & $-3.54 * * * *$ & 6.69 & 6.48 & 9.54 & 8.56 & $-3.73 * * *$ & 6.55 & 6.97 & 9.01 & 8.22 & $-3.05 * * *$ \\
\hline Top5_Shrout & 0.24 & 0.09 & 0.23 & 0.09 & 0.31 & 0.25 & 0.09 & 0.22 & 0.08 & $3.15^{* * * *}$ & 0.27 & 0.09 & 0.24 & 0.09 & $3.13 * * *$ \\
\hline Obs & 39 & & 11 & & & 52 & 23 & 16 & & & 53 & 38 & 13 & & \\
\hline$\%$ of firms & 77. & & 22. & & & 76. & & 23. & & & 80. & $2 \%$ & 19.8 & $8 \%$ & \\
\hline
\end{tabular}


Table 4: Board structure and institutional trader monitoring between compliant and noncompliant firms pre-SOX (1996-2000)

This table reports the results from regressing board independence (Columns 1 to 3) and size (Columns 4 to 6) on the Swing trading measures (turnover of the institutional investor engaging in the "Buy-Sell-Buy" trading pattern), along with the control variables. We estimate a restricted model (assume coefficients on all the controls equal to zero) in Columns (1) and (4). Columns (2) and (5) include control variables in the estimation. In Columns (3) and (6) We use common factor analysis to extract a factor score (Score_ADVICE) from the four variables derived from the scope of operations hypothesis (Ln_Sales, Debt_Ratio, Ln_NumSegments, and Ln_FirmAge). Noncompliant (with one-year lag) is a dummy variable that equals one if the majority of the directors on the board is insiders and zero otherwise. All the other variables are defined in Table 1, except variables prefixed with $L n_{-}$, representing the natural log. The sample consists of ExecuComp/RiskMetrics firms from 1996 to 2000 but firms in the financial and highly regulated industries (two-digit SIC code=49, 60-69) are excluded. We report t-statistics robust to heteroscedasticity and adjusted for firm-level clustering. The asterisks indicate statistical significance at the $1 \%(* * *), 5 \%(* *)$, and $10 \%(*)$ levels. 


\begin{tabular}{|c|c|c|c|c|c|c|}
\hline & \multicolumn{3}{|c|}{ Board independence } & \multicolumn{3}{|c|}{ Board size } \\
\hline & (1) & (2) & (3) & (4) & (5) & (6) \\
\hline \multirow[t]{2}{*}{ Intercept } & $57.27 * * * *$ & 54.95 **** & $67.77^{* * * * *}$ & $9.36^{* * * *}$ & $3.48^{* * * *}$ & $11.60^{* * * *}$ \\
\hline & $(82.80)$ & $(8.59)$ & $(20.71)$ & $(12.76)$ & $(2.76)$ & $(13.72)$ \\
\hline \multirow[t]{2}{*}{ Swing } & $39.11^{* * *}$ & $33.98^{*}$ & $33.30^{*}$ & -0.083 & 0.83 & 1.84 \\
\hline & $(2.02)$ & $(1.73)$ & $(1.70)$ & $(-0.02)$ & $(0.30)$ & $(0.65)$ \\
\hline \multirow[t]{2}{*}{ Ln_Sales } & & 0.48 & & & $0.72^{* * * *}$ & \\
\hline & & $(1.06)$ & & & $(8.90)$ & \\
\hline \multirow[t]{2}{*}{ Debt_Ratio } & & $6.52 *$ & & & 0.46 & \\
\hline & & $(1.77)$ & & & $(0.74)$ & \\
\hline \multirow[t]{2}{*}{ Ln_NumSegments } & & $1.96^{* * * * *}$ & & & 0.09 & \\
\hline & & $(2.57)$ & & & $(0.65)$ & \\
\hline \multirow[t]{2}{*}{ Ln_FirmAge } & & $1.22 *$ & & & $0.39^{* * * * *}$ & \\
\hline & & $(1.71)$ & & & $(3.46)$ & \\
\hline \multirow[t]{2}{*}{ Score_ADVICE } & & & $3.67^{* * * * *}$ & & & 1.59 **** \\
\hline & & & $(4.17)$ & & & (11.44) \\
\hline \multirow[t]{2}{*}{ Market-to-book } & & -0.014 & -0.012 & & $-0.004 *$ & $-0.0047 * *$ \\
\hline & & $(-0.92)$ & $(-0.82)$ & & $(-1.86)$ & $(-2.04)$ \\
\hline \multirow[t]{2}{*}{$\mathrm{R} \& \mathrm{D} / \mathrm{A}$} & & $34.67^{* * * *}$ & $29.85^{* * *}$ & & 1.06 & $3.48^{*}$ \\
\hline & & $(2.81)$ & $(2.47)$ & & $(0.52)$ & $(1.70)$ \\
\hline Lag_Ret_Volat & & $-11.50^{* * * *}$ & $-11.51^{* * * *}$ & & $-3.61 * * *$ & $-4.067 * * *$ \\
\hline & & $(-2.60)$ & $(-2.63)$ & & $(-5.74)$ & $(-6.47)$ \\
\hline FCF & & -3.91 & -5.60 & & $-2.11^{* *}$ & -1.02 \\
\hline & & $(-0.70)$ & $(-1.03)$ & & $(-2.09)$ & $(-1.11)$ \\
\hline Industry Herfindahl & & 6.71 & 7.36 & & 0.11 & 0.089 \\
\hline & & $(0.83)$ & $(0.91)$ & & $(0.12)$ & $(0.09)$ \\
\hline PPS_Total & & $-0.044 * * * *$ & $-0.045 * * * *$ & & $-0.004 * *$ & $-0.006^{* * * * *}$ \\
\hline & & $(-3.76)$ & $(-3.89)$ & & $(-1.97)$ & $(-2.68)$ \\
\hline Lag_ROA & & -5.60 & -7.78 & & & \\
\hline & & $(-0.92)$ & $(-1.27)$ & & & \\
\hline Ln_CEOTenure & & $-1.01 *$ & $-0.98^{*}$ & & & \\
\hline & & $(-1.94)$ & $(-1.86)$ & & & \\
\hline Top5_Shrout & & $25.14^{* * * * *}$ & $26.66 * * * *$ & & $-2.05^{* *}$ & $-2.98^{* * * *}$ \\
\hline & & (4.44) & $(4.91)$ & & $(-2.18)$ & $(-3.25)$ \\
\hline Non-compliant dummy & $-27.59^{* * * *}$ & -10.56 & $-24.96 * * * *$ & $-0.67 * * *$ & -2.26 & -0.51 \\
\hline & $(-24.28)$ & $(-0.88)$ & $(-4.98)$ & $(-2.66)$ & $(-1.24)$ & $(-0.67)$ \\
\hline Swing $x$ Non-compliant & -39.09 & -49.21 & -60.55 & -3.84 & -2.71 & -4.19 \\
\hline & $(-1.00)$ & $(-1.21)$ & $(-1.47)$ & $(-0.50)$ & $(-0.39)$ & $(-0.62)$ \\
\hline Sales $x$ Non-compliant & & -1.73 & & & -0.12 & \\
\hline & & $(-1.64)$ & & & $(-0.80)$ & \\
\hline Leverage $X$ Non-compliant & & $-12.44 * *$ & & & 0.04 & \\
\hline & & $(-2.07)$ & & & $(0.04)$ & \\
\hline NumSegments X Non-compliant & & -1.32 & & & 0.22 & \\
\hline & & $(-0.82)$ & & & $(0.81)$ & \\
\hline FirmAge $x$ Non-compliant & & 0.31 & & & $0.57^{* * * * *}$ & \\
\hline & & $(0.19)$ & & & $(2.36)$ & \\
\hline Score_ADVICE X Non-compliant & & & $-5.02 * *$ & & & 0.37 \\
\hline & & & $(-2.53)$ & & & $(1.18)$ \\
\hline MTB X Non-compliant & & 0.004 & 0.009 & & $0.01^{* * *}$ & $0.0098 *$ \\
\hline & & $(0.12)$ & $(0.27)$ & & $(2.28)$ & (1.84) \\
\hline RD $\times$ Non-compliant & & 5.09 & 11.67 & & -4.23 & $-8.45^{* * *}$ \\
\hline & & $(0.18)$ & $(0.41)$ & & $(-1.21)$ & $(-1.98)$ \\
\hline LagRetVolat X Non-compliant & & 0.91 & 0.37 & & 0.57 & 0.65 \\
\hline & & $(0.13)$ & $(0.05)$ & & $(0.55)$ & $(0.61)$ \\
\hline FCF $\times$ Non-compliant & & 9.68 & 11.97 & & -0.57 & -1.68 \\
\hline & & $(0.91)$ & $(1.12)$ & & $(-0.32)$ & $(-1.03)$ \\
\hline Ind_Herfindahl X Non-compliant & & 9.40 & 6.98 & & 1.63 & 1.74 \\
\hline & & $(1.00)$ & $(0.72)$ & & $(1.10)$ & $(1.21)$ \\
\hline PPS_Total X Non-compliant & & $0.029 *$ & $0.03 *$ & & -0.0002 & 0.002 \\
\hline & & $(1.80)$ & $(1.87)$ & & $(-0.08)$ & $(0.63)$ \\
\hline LagROA x Non-compliant & & 0.48 & 4.26 & & & \\
\hline & & $(0.04)$ & $(0.33)$ & & & \\
\hline CEOTenure X Non-compliant & & 0.24 & 0.33 & & & \\
\hline & & $(0.22)$ & $(0.30)$ & & & \\
\hline Top5_Shrout X Non-compliant & & -14.72 & -17.70 & & -0.81 & 0.17 \\
\hline & & $(-1.27)$ & $(-1.51)$ & & $(-0.46)$ & $(0.09)$ \\
\hline Year effect & Yes & Yes & Yes & Yes & Yes & Yes \\
\hline Industry effect & Yes & Yes & Yes & Yes & Yes & Yes \\
\hline $\begin{array}{l}\text { R-squared } \\
\text { R }\end{array}$ & 0.5161 & 0.5805 & 0.5772 & 0.1943 & 0.4851 & 0.4647 \\
\hline Observations & 1928 & 1623 & 1623 & 1929 & 1889 & 1889 \\
\hline
\end{tabular}




\section{Table 5: Board structure and institutional trader monitoring after SOX (2002-2007)}

This table reports the results from regressing board independence (Columns 1 to 3 ) and size (Columns 4 to 6 ) on the Swing trading measures (turnover of the institutional investor engaging in the "Buy-Sell-Buy" trading pattern), along with the control variables. We estimate a restricted model (assume coefficients on all the controls equal to zero) in Columns (1) and (4). Columns (2) and (5) include control variables in the estimation. In Columns (3) and (6) We use common factor analysis to extract a factor score (Score_ADVICE) from the four variables derived from the scope of operations hypothesis (Ln_Sales, Debt_Ratio, Ln_NumSegments, and Ln_FirmAge). All the other variables are defined in Table 1, except variables prefixed with $L n_{-}$, representing the natural log. The sample consists of ExecuComp/RiskMetrics firms from 2002 to 2007 but firms in the financial and highly regulated industries (two-digit SIC code=49, 60-69) are excluded. We report t-statistics robust to heteroscedasticity and adjusted for firm-level clustering. The asterisks indicate statistical significance at the $1 \%(* * *), 5 \%(* *)$, and $10 \%(*)$ levels.

\begin{tabular}{|c|c|c|c|c|c|c|}
\hline & \multicolumn{3}{|c|}{ Board independence } & \multicolumn{3}{|c|}{ Board size } \\
\hline & (1) & $(2)$ & (3) & (4) & $(5)$ & (6) \\
\hline \multirow[t]{2}{*}{ Intercept } & 70.71 & $57.11 * * *$ & $77.38 * * *$ & 10.38 & $3.59 * * *$ & $10.38 * * *$ \\
\hline & (10.49) & (9.55) & (18.43) & $(10.96)$ & (4.05) & (14.88) \\
\hline \multirow[t]{2}{*}{ Swing } & $18.79 *$ & $23.41 * *$ & $25.97 * *$ & $-3.99 * *$ & $-2.67 *$ & -1.18 \\
\hline & $(1.69)$ & (2.13) & (2.37) & $(-2.40)$ & $(-1.94)$ & $(-0.82)$ \\
\hline \multirow[t]{2}{*}{ Ln_Sales } & & $1.47 * * *$ & & & $0.60 * * *$ & \\
\hline & & $(4.27)$ & & & (11.89) & \\
\hline \multirow[t]{2}{*}{ Debt_Ratio } & & 1.79 & & & $1.05 * * *$ & \\
\hline & & $(0.64)$ & & & (2.95) & \\
\hline \multirow[t]{2}{*}{ Ln_NumSegments } & & -0.39 & & & 0.16 & \\
\hline & & $(-0.54)$ & & & $(1.65)$ & \\
\hline \multirow[t]{2}{*}{ Ln_FirmAge } & & $1.40 * *$ & & & $0.29 * * *$ & \\
\hline & & $(2.21)$ & & & (3.30) & \\
\hline \multirow[t]{2}{*}{ Score_ADVICE } & & & $3.48 * * *$ & & & $1.42 * * *$ \\
\hline & & & (4.72) & & & $(15.30)$ \\
\hline \multirow[t]{2}{*}{ Market-to-book } & & -0.006 & -0.007 & & -0.001 & -0.001 \\
\hline & & $(-0.49)$ & $(-0.54)$ & & $(-0.84)$ & $(-0.81)$ \\
\hline \multirow[t]{2}{*}{$\mathrm{R} \& \mathrm{D} / \mathrm{A}$} & & -2.02 & 0.79 & & -0.024 & 0.34 \\
\hline & & $(-0.18)$ & $(0.07)$ & & $(-0.02)$ & $(0.23)$ \\
\hline \multirow[t]{2}{*}{ Lag_Ret_Volat } & & -3.82 & $-4.77 *$ & & $-1.16^{* * *}$ & $-1.43 * * *$ \\
\hline & & $(-1.40)$ & $(-1.77)$ & & $(-3.60)$ & $(-4.33)$ \\
\hline \multirow[t]{2}{*}{$\mathrm{FCF}$} & & 3.33 & 4.97 & & $-1.60 * * *$ & -0.84 \\
\hline & & $(0.68)$ & $(1.03)$ & & $(-2.69)$ & $(-1.48)$ \\
\hline \multirow[t]{2}{*}{ Industry Herfindahl } & & 0.13 & -0.43 & & $0.75^{*}$ & 0.56 \\
\hline & & $(0.03)$ & $(-0.09)$ & & (1.67) & $(1.26)$ \\
\hline \multirow[t]{2}{*}{ PPS_Total } & & $-0.04 * * *$ & $-0.05 * * *$ & & $-0.004 * * *$ & $-0.004 * * *$ \\
\hline & & $(-5.70)$ & $(-5.81)$ & & $(-3.54)$ & $(-3.98)$ \\
\hline \multirow[t]{2}{*}{ Lag_ROA } & & -5.20 & -4.20 & & & \\
\hline & & $(-1.34)$ & $(-1.09)$ & & & \\
\hline \multirow[t]{2}{*}{ Ln_CEOTenure } & & -0.31 & -0.31 & & & \\
\hline & & $(-0.76)$ & $(-0.75)$ & & & \\
\hline \multirow[t]{2}{*}{ Top5_Shrout } & & $16.19 * * *$ & $14.45^{* * *}$ & & $-2.71 * * *$ & $-3.26 * * *$ \\
\hline & & (3.35) & (3.04) & & $(-4.23)$ & $(-5.04)$ \\
\hline Year effect & Yes & Yes & Yes & Yes & Yes & Yes \\
\hline Industry effect & Yes & Yes & Yes & Yes & Yes & Yes \\
\hline R-squared & 0.1405 & 0.2401 & 0.2346 & 0.1641 & 0.4469 & 0.423 \\
\hline Observations & 3814 & 3182 & 3182 & 3814 & 3648 & 3648 \\
\hline
\end{tabular}


Table 6: Board structure and institutional trader monitoring-SOX and compliance

This table reports the results from regressing board independence (Columns 1 to 3 ) and size (Columns 4 to 6) on the Swing trading measures (turnover of the institutional investor engaging in the "Buy-Sell-Buy" trading pattern), the interaction of Swing with the POSTSOX dummy and the Non-compliant dummy variables, along with the control variables. POSTSOX takes the value of 1 if the sample year is after (including) 2003 and zero otherwise. Non-compliant (with one-year lag) equals one if the majority of the directors on the board is insiders and zero otherwise. In Columns (1) and (4), we include only the POSTSOX dummy in the regression, whereas in

Columns (2) and (5), we include the interaction of each of the regressors with the POSTSOX dummy in the regression. In Columns (3) and (6), we consider also the Non-compliant dummy. All the other variables are defined in Table 1, except score_ADVICE (defined in Table 3) and variables prefixed with $L n_{-}$, representing the natural log. The sample consists of ExecuComp/RiskMetrics firms from 1998 to 2007 but firms in the financial and highly regulated industries (two-digit SIC code $=49,60-69$ ) are excluded. We report t-statistics robust to heteroscedasticity and adjusted for firm-level clustering. The asterisks indicate statistical significance at the $1 \%$

\begin{tabular}{|c|c|c|c|c|c|c|}
\hline & \multicolumn{3}{|c|}{ Board independence } & \multicolumn{3}{|c|}{ Board size } \\
\hline & (1) & (2) & (3) & (4) & (5) & (6) \\
\hline \multirow[t]{2}{*}{ Intercept } & $66.77 * * *$ & $64.06^{* * *}$ & $76.81 * * *$ & $10.73^{* * *} *$ & $10.58^{* * *}$ & $9.78^{* * *}$ \\
\hline & (14.33) & (15.35) & (13.55) & (16.48) & (15.49) & (13.98) \\
\hline \multirow[t]{2}{*}{ Swing } & $32.35^{* * * *}$ & $26.38^{*}$ & $24.01 *$ & -0.79 & 0.06 & 0.73 \\
\hline & (3.26) & $(1.77)$ & $(1.69)$ & $(-0.68)$ & $(0.04)$ & $(0.35)$ \\
\hline \multirow[t]{2}{*}{ Swing $\times$ POSTSOX } & & 7.30 & -6.69 & & -1.65 & -0.68 \\
\hline & & $(0.40)$ & $(-0.39)$ & & $(-0.81)$ & $(-0.28)$ \\
\hline \multirow[t]{2}{*}{ Swing $\times$ Non-compliant } & & & $-61.38^{* * *}$ & & & -4.56 \\
\hline & & & $(-2.30)$ & & & $(-1.03)$ \\
\hline \multirow[t]{2}{*}{ Swing $\times$ POSTSOX $\times$ Non-compliant } & & & $115.45^{* * *}$ & & & 1.83 \\
\hline & & & (3.48) & & & $(0.34)$ \\
\hline \multirow[t]{2}{*}{ POSTSOX dummy } & $5.99 * * *$ & $14.09 * * *$ & $1.91^{* * *}$ & $-0.31 * * *$ & -0.33 & $-0.25 * * *$ \\
\hline & $(10.87)$ & (5.02) & (2.97) & $(-4.78)$ & $(-1.00)$ & $(-2.68)$ \\
\hline \multirow[t]{2}{*}{ Non-compliant dummy } & & & $-24.19 * * *$ & & & 0.2 \\
\hline & & & $(-23.20)$ & & & (1.18) \\
\hline \multirow[t]{2}{*}{ Score_ADVICE } & $5.07 * * *$ & $6.20 * * *$ & $2.86^{* * *}$ & $1.56^{* * * *}$ & $1.72 * * *$ & $1.59 * * *$ \\
\hline & (7.84) & (7.67) & (5.33) & (19.11) & (17.48) & (17.44) \\
\hline \multirow[t]{2}{*}{ Market-to-book } & -0.0062 & -0.004 & -0.006 & -0.002 & -0.002 & $-0.0022 *$ \\
\hline & $(-0.59)$ & $(-0.28)$ & $(-0.77)$ & $(-1.61)$ & $(-0.95)$ & $(-1.65)$ \\
\hline \multirow[t]{2}{*}{$\mathrm{R} \& \mathrm{D} / \mathrm{A}$} & 15.25 & $21.84 *$ & 5.36 & -0.21 & -0.08 & -0.126 \\
\hline & $(1.56)$ & $(1.89)$ & $(0.71)$ & $(-0.16)$ & $(-0.05)$ & $(-0.09)$ \\
\hline \multirow[t]{2}{*}{ Lag_Ret_Volat } & -3.18 & 0.37 & $-7.23 * * *$ & $-1.47 * * *$ & $-1.60 * * *$ & $-1.37 * * *$ \\
\hline & $(-1.51)$ & $(0.14)$ & $(-3.79)$ & $(-6.34)$ & $(-5.79)$ & $(-4.61)$ \\
\hline \multirow[t]{2}{*}{ FCF } & 1.045 & 0.75 & -1.59 & -0.54 & -0.26 & -0.802 \\
\hline & $(0.26)$ & $(0.15)$ & $(-0.50)$ & $(-1.04)$ & $(-0.41)$ & $(-1.39)$ \\
\hline \multirow[t]{2}{*}{ Industry Herfindahl } & 0.85 & 1.92 & -0.14 & 0.44 & 0.52 & 0.63 \\
\hline & $(0.20)$ & (0.38) & $(-0.04)$ & (1.00) & $(0.91)$ & (1.37) \\
\hline \multirow[t]{2}{*}{ PPS_Total } & $-0.043 * * *$ & $-0.045^{* * *}$ & $-0.029 * * *$ & $-0.004 * * *$ & $-0.004 * * *$ & $-0.004 * * *$ \\
\hline & $(-6.11)$ & $(-5.06)$ & $(-5.75)$ & $(-3.79)$ & $(-2.65)$ & $(-3.52)$ \\
\hline Lag_ROA & -1.046 & -3.68 & -2.89 & & & \\
\hline & $(-0.31)$ & $(-0.82)$ & $(-1.04)$ & & & \\
\hline Ln_CEOTenure & $-0.79 * *$ & $-1.44 * * *$ & $-0.56^{* *}$ & & & \\
\hline & $(-2.15)$ & $(-2.97)$ & $(-1.96)$ & & & \\
\hline Top5_Shrout & $27.87^{* * *}$ & $37.52 * * *$ & $14.20^{* * *}$ & $-2.97 * * *$ & $-2.85^{* * *}$ & $-2.92^{* * *}$ \\
\hline & (6.64) & (7.03) & (4.42) & $(-5.37)$ & $(-4.20)$ & $(-4.86)$ \\
\hline Score_ADVICE X POSTSOX & & $-2.47 * * *$ & & & $-0.30 * * *$ & \\
\hline & & $(-2.94)$ & & & $(-2.99)$ & \\
\hline MTB $\times$ POSTSOX & & -0.002 & & & -0.001 & \\
\hline & & $(-0.10)$ & & & $(-0.55)$ & \\
\hline RD X POSTSOX & & -15.44 & & & -0.07 & \\
\hline & & $(-1.27)$ & & & $(-0.05)$ & \\
\hline LagRetVolat X POSTSOX & & $-9.10 * * *$ & & & 0.55 & \\
\hline & & $(-2.97)$ & & & $(1.61)$ & \\
\hline FCF $\times$ POSTSOX & & 0.11 & & & -0.65 & \\
\hline & & $(-0.02)$ & & & $(-0.94)$ & \\
\hline Ind_Herfindahl X POSTSOX & & -3.37 & & & 0.25 & \\
\hline & & $(-0.81)$ & & & $(0.55)$ & \\
\hline PPS_Total X POSTSOX & & 0.003 & & & -0.0010 & \\
\hline & & $(0.35)$ & & & $(-0.79)$ & \\
\hline LagROA x POSTSOX & & 5.09 & & & & \\
\hline & & $(0.86)$ & & & & \\
\hline CEOTenure $\mathrm{X}$ POSTSOX & & $1.43^{* *}$ & & & & \\
\hline & & (2.49) & & & & \\
\hline Top5_Shrout X POSTSOX & & $-21.95^{* * *}$ & & & -0.33 & \\
\hline & & $(-3.69)$ & & & $(-0.43)$ & \\
\hline Industry effect & Yes & Yes & $\overline{\text { Yes }}$ & Yes & Yes & Yes \\
\hline R-squared & 0.2479 & 0.2564 & 0.4950 & 0.4315 & 0.4349 & 0.4231 \\
\hline Observations & 5170 & 5170 & 4725 & 6043 & 6043 & $\begin{array}{r}5313 \\
\end{array}$ \\
\hline
\end{tabular}

Table 7: Robustness checks: endogeneity 
This table reports the results from regressing board independence on the Swing trading measures (turnover of the institutional investor engaging in the "Buy-Sell-Buy" trading pattern), along with control variables. In Column (1) We include firm fixed effects in the estimation. Columns (2) and (3) report the results from using 2SLS estimation, using Ln_AnalystCov as the instrumental variable. Column (4) presents estimates using the lagged values of the regressors in the regression. Column (5) uses lagged board independence as the dependent variable in the regression. All the other variables are defined in Table 1, except Ln_AnalystCov and variables prefixed with $L n \_$, representing the natural $\log$. $L n \_$AnalystCov is defined as the log of the number of analysts following a firm. The sample consists of ExecuComp/RiskMetrics firms from 1996 to 2007 but firms in the financial and highly regulated industries (two-digit SIC code=49, 60-69) are excluded. We report t-statistics robust to heteroscedasticity and adjusted for firm-level clustering (except for the firm fixed effect regression, which is robust to heteroscedasticity only). The asterisks indicate statistical significance at the $1 \%(* * *), 5 \%(* *)$, and $10 \%(*)$ levels.

\begin{tabular}{|c|c|c|c|c|c|}
\hline \multicolumn{6}{|c|}{ Dependent variable: Board independence } \\
\hline & \multirow{3}{*}{ Firm fixed effect } & $(2)$ & (3) & $(4)$ & \multirow{3}{*}{$\begin{array}{c}\text { Lagged value of } \\
\text { board independence }\end{array}$} \\
\hline & & \multicolumn{2}{|c|}{ 2SLS } & \multirow{2}{*}{$\begin{array}{l}\text { Lagged values } \\
\text { of regressors }\end{array}$} & \\
\hline & & First stage & Second stage & & \\
\hline \multirow[t]{2}{*}{ Intercept } & $54.91 * * *$ & $0.03^{* * *}$ & $56.17 * * *$ & $44.98 * * *$ & $41.89^{* * * *}$ \\
\hline & (6.58) & $(4.24)$ & $(8.00)$ & (6.38) & (6.26) \\
\hline \multirow[t]{2}{*}{ Swing } & $12.61 * *$ & & $194.15^{*}$ & $20.06^{* *}$ & $22.14 * *$ \\
\hline & $(1.96)$ & & $(1.71)$ & $(1.97)$ & $(2.08)$ \\
\hline \multirow[t]{2}{*}{ Ln_Sales } & 0.13 & -0.0006 & $0.95 * *$ & $1.43^{* * * *}$ & $1.25 * * *$ \\
\hline & $(0.23)$ & $(-1.53)$ & $(2.37)$ & $(3.82)$ & $(3.30)$ \\
\hline \multirow[t]{2}{*}{ Debt_Ratio } & -1.73 & 0.003 & -0.39 & 1.01 & 2.04 \\
\hline & $(-0.91)$ & $(1.14)$ & $(-0.14)$ & $(0.34)$ & $(0.70)$ \\
\hline \multirow[t]{2}{*}{ Ln_NumSegments } & $1.11^{* *}$ & 0.0005 & $1.26 * *$ & 0.47 & 0.8 \\
\hline & $(2.34)$ & $(0.78)$ & $(1.97)$ & $(0.72)$ & $(1.14)$ \\
\hline \multirow[t]{2}{*}{ Ln_FirmAge } & $2.93 * *$ & $-0.001 * * *$ & $2.47 * * *$ & $2.28 * * *$ & $2.27 * * *$ \\
\hline & $(2.54)$ & $(-2.80)$ & (4.13) & (3.96) & (3.71) \\
\hline \multirow[t]{2}{*}{ Market-to-book } & 0.0032 & $-9.70 e-06$ & -0.007 & $-0.022 * *$ & -0.01 \\
\hline & $(0.51)$ & $(-0.71)$ & $(-0.63)$ & $(-2.20)$ & $(-1.00)$ \\
\hline \multirow[t]{2}{*}{$\mathrm{R} \& \mathrm{D} / \mathrm{A}$} & $17.58 * *$ & 0.005 & $21.95^{* *}$ & $19.53 *$ & 13.73 \\
\hline & (2.03) & $(0.50)$ & (2.36) & (1.87) & $(1.30)$ \\
\hline \multirow[t]{2}{*}{ Lag_Ret_Volat } & $-4.86^{* * *}$ & $0.02 * * *$ & $-9.93 * * *$ & -3.84 & $-7.44 * *$ \\
\hline & $(-2.96)$ & $(6.56)$ & $(-2.82)$ & $(-1.25)$ & $(-2.56)$ \\
\hline \multirow[t]{2}{*}{ FCF } & 1.92 & $0.01 * * *$ & 1.25 & 4.26 & 2.85 \\
\hline & $(0.70)$ & (2.69) & $(0.30)$ & (1.03) & $(0.65)$ \\
\hline \multirow[t]{2}{*}{ Industry Herfindahl } & -3.07 & $0.01 *$ & $-8.03^{*}$ & -6.25 & -1.54 \\
\hline & $(-0.97)$ & $(1.74)$ & $(-1.74)$ & $(-1.33)$ & $(-0.33)$ \\
\hline \multirow[t]{2}{*}{ PPS_Total } & $-0.01^{*}$ & -0.0000101 & $-0.05 * * *$ & $-0.046 * * *$ & $-0.049 * * *$ \\
\hline & $(-1.67)$ & $(-1.33)$ & $(-6.11)$ & $(-6.80)$ & $(-6.80)$ \\
\hline \multirow[t]{2}{*}{ Lag_ROA } & 0.30 & $0.013 * * *$ & $-9.17 * *$ & $-8.46^{* *}$ & -4.60 \\
\hline & $(0.13)$ & (2.62) & $(-2.28)$ & $(-2.31)$ & $(-1.26)$ \\
\hline \multirow[t]{2}{*}{ Ln_CEOTenure } & $0.50 * *$ & 0.0002 & $-0.77 * *$ & $-1.12 * * *$ & -0.41 \\
\hline & $(2.35)$ & (0.48) & $(-2.15)$ & $(-2.98)$ & $(-1.09)$ \\
\hline \multirow[t]{2}{*}{ Top5_Shrout } & $6.59 * *$ & $0.018 * * *$ & $22.03 * * *$ & $27.57 * * *$ & $25.39 * * *$ \\
\hline & $(2.31)$ & $(4.50)$ & (4.61) & (6.00) & (5.45) \\
\hline \multirow[t]{2}{*}{ Ln_AnalystCoverage } & & $0.006 * * *$ & & & \\
\hline & & $(9.86)$ & & & \\
\hline Year effect & Yes & Yes & Yes & Yes & Yes \\
\hline Industry effect & No & Yes & Yes & Yes & Yes \\
\hline Firm effect & Yes & No & No & No & No \\
\hline$\overline{R \text {-squared }}$ & 0.7731 & 0.1425 & 0.2097 & 0.2772 & 0.2446 \\
\hline Observations & 6010 & 5936 & 5936 & 5155 & 5222 \\
\hline
\end{tabular}




\section{Table 8: Robustness checks: alternative measures of institutional trader monitoring}

This table reports the results from regressing board independence on the alternative measures of Swing trading measures (turnover of the institutional investor engaging in the "Buy-Sell-Buy" trading pattern), along with the control variables. Column (1) uses Swing as proxy for institutional investor monitoring. Columns (2) and (3) use Ln_Num_mgr and Turnover_TRA as the alternative measures in the regression, respectively. Ln_Num_Mgr is defined as the natural log of the number of institutional investors engaging in the "Buy-Sell-Buy" trading pattern for a firm in a year. Turnover_TRA is the turnover of the transient group of institutional investors (classified by Bushee $(1998,2001))$ for a firm in a year. All the other variables are defined in Table 1, except variables prefixed with $L n_{-}$, representing the natural log. The sample consists of ExecuComp/RiskMetrics firms from 1996 to 2007 but firms in the financial and highly regulated industries (two-digit SIC code=49, 60-69) are excluded. We report t-statistics robust to heteroscedasticity and adjusted for firm-level clustering. The asterisks indicate statistical significance at the $1 \%(* * *), 5 \%(* *)$, and $10 \%(*)$ levels.

\begin{tabular}{|c|c|c|c|}
\hline \multicolumn{4}{|c|}{ Dependent variable: Board independence } \\
\hline & $(1)$ & $(2)$ & (3) \\
\hline \multirow[t]{2}{*}{ Intercept } & $82.28 * * *$ & $80.81 * * *$ & $83.74 * * *$ \\
\hline & (19.73) & $(19.26)$ & $(21.51)$ \\
\hline \multirow[t]{2}{*}{ Swing } & $26.63 * *$ & & \\
\hline & (2.72) & & \\
\hline \multirow[t]{2}{*}{ Ln_Num_Mgr } & & $0.97 * *$ & \\
\hline & & $(2.03)$ & \\
\hline \multirow[t]{2}{*}{ Turnover_TRA } & & & $20.22 * * *$ \\
\hline & & & (3.77) \\
\hline \multirow[t]{2}{*}{ Score_ADVICE } & $4.65 * * *$ & $4.06 * * *$ & $4.67 * * *$ \\
\hline & (7.42) & (5.92) & (7.49) \\
\hline \multirow[t]{2}{*}{ Market-to-book } & -0.01 & -0.01 & -0.01 \\
\hline & $(-0.97)$ & $(-0.92)$ & $(-0.60)$ \\
\hline \multirow[t]{2}{*}{$\mathrm{R} \& \mathrm{D} / \mathrm{A}$} & $18.66 * *$ & $15.69^{*}$ & $19.39 * *$ \\
\hline & $(2.01)$ & $(1.70)$ & $(2.10)$ \\
\hline \multirow[t]{2}{*}{ Lag_Ret_Volat } & $-6.34 * *$ & $-5.93 * *$ & $-7.11 * * *$ \\
\hline & $(-2.39)$ & $(-2.24)$ & $(-2.71)$ \\
\hline \multirow[t]{2}{*}{ FCF } & 3.73 & 3.17 & 1.93 \\
\hline & $(0.97)$ & $(0.83)$ & $(0.50)$ \\
\hline \multirow[t]{2}{*}{ Industry Herfindahl } & -6.45 & -6.26 & $-8.25^{*}$ \\
\hline & $(-1.51)$ & $(-1.46)$ & $(-1.86)$ \\
\hline \multirow[t]{2}{*}{ PPS_Total } & $-0.05 * * *$ & $-0.05 * * *$ & $-0.04 * * *$ \\
\hline & $(-7.12)$ & $(-6.91)$ & $(-6.72)$ \\
\hline \multirow[t]{2}{*}{ Lag_ROA } & -5.10 & $-6.19 *$ & $-5.75 *$ \\
\hline & $(-1.51)$ & $(-1.84)$ & $(-1.68)$ \\
\hline \multirow[t]{2}{*}{ Ln_CEOTenure } & $-0.69 *$ & $-0.70 * *$ & $-0.75 * *$ \\
\hline & $(-1.95)$ & $(-1.98)$ & $(-2.14)$ \\
\hline \multirow[t]{2}{*}{ Top5_Shrout } & $23.83 * * *$ & $25.68 * * *$ & $23.97 * * *$ \\
\hline & $(5.70)$ & (6.08) & (5.74) \\
\hline Year effect & Yes & Yes & Yes \\
\hline Industry effect & Yes & Yes & Yes \\
\hline R-squared & 0.2624 & 0.2626 & 0.2686 \\
\hline Observations & 6010 & 6010 & 6128 \\
\hline
\end{tabular}




\section{Table 9: Robustness checks: adoption of antitakeover provisions}

This table reports the results from regressing board independence on the alternative measures of Swing trading measures (turnover of the institutional investor engaging in the "Buy-Sell-Buy" trading pattern), along with the antitakeover provision dummies and other control variables. In Columns (1) to Column (3) we use Swing, Ln_Num_mgr and Turnover_TRA as the proxies for institutional investor monitoring in the regression, respectively. Ln_Num_Mgr is defined as the natural log of the number of institutional investors engaging in the "Buy-Sell-Buy" trading pattern for a firm in a year. Turnover_TRA is the turnover of the transient group of institutional investors (classified by Bushee $(1998,2001)$ ) for a firm in a year. All the other variables are defined in Table 1, except the takeover defense dummies and variables prefixed with $L n_{-}$, representing the natural log. Takeover defense dummy variables include PPILL (poison pill), CBOARD (staggered board), CUMVOTE (cumulative voting), and SUPERMAJOR (supermajority voting requirements). These dummy variables take value of 1 if a firm adopts the corresponding antitakeover provision(s) and zero otherwise. The sample consists of ExecuComp/RiskMetrics firms from 1996 to 2007 but firms in the financial and highly regulated industries (twodigit SIC code $=49,60-69$ ) are excluded. We report t-statistics robust to heteroscedasticity and adjusted for firmlevel clustering. The asterisks indicate statistical significance at the $1 \%(* * *), 5 \%(* *)$, and 10\%(*) levels.

\begin{tabular}{|c|c|c|c|}
\hline \multicolumn{4}{|c|}{ Dependent variable: Board independence } \\
\hline & $(1)$ & $(2)$ & (3) \\
\hline \multirow[t]{2}{*}{ Intercept } & $78.59 * * *$ & $77.27 * * *$ & $79.08 * * *$ \\
\hline & (19.74) & (18.59) & (18.72) \\
\hline \multirow[t]{2}{*}{ Swing } & $24.11^{*}$ & & \\
\hline & $(1.93)$ & & \\
\hline \multirow[t]{2}{*}{ Ln_Num_Mgr } & & $0.90 *$ & \\
\hline & & $(1.69)$ & \\
\hline \multirow[t]{2}{*}{ Turnover_TRA } & & & $16.77 * * *$ \\
\hline & & & (2.76) \\
\hline \multirow[t]{2}{*}{ Score_ADVICE } & $4.67 * * *$ & $4.11 * * *$ & $4.53 * * *$ \\
\hline & $(6.73)$ & $(5.37)$ & $(6.51)$ \\
\hline \multirow[t]{2}{*}{ Market-to-book } & -0.0088 & -0.008 & -0.011 \\
\hline & $(-0.66)$ & $(-0.62)$ & $(-0.85)$ \\
\hline \multirow[t]{2}{*}{$\mathrm{R} \& \mathrm{D} / \mathrm{A}$} & 14.79 & 11.53 & 14.86 \\
\hline & $(1.48)$ & $(1.15)$ & $(1.50)$ \\
\hline \multirow[t]{2}{*}{ Lag_Ret_Volat } & $-6.14 * *$ & $-5.80 * *$ & $-6.42 * *$ \\
\hline & $(-2.16)$ & $(-2.05)$ & $(-2.24)$ \\
\hline \multirow[t]{2}{*}{ FCF } & 3.13 & 2.79 & 2.10 \\
\hline & $(0.73)$ & $(0.64)$ & $(0.48)$ \\
\hline \multirow[t]{2}{*}{ Industry Herfindahl } & -8.37 & -8.47 & $-9.04 *$ \\
\hline & $(-1.61)$ & $(-1.63)$ & $(-1.73)$ \\
\hline \multirow[t]{2}{*}{ PPS_Total } & $-0.035 * * *$ & $-0.034 * * *$ & $-0.033 * * *$ \\
\hline & $(-4.89)$ & $(-4.69)$ & $(-4.70)$ \\
\hline \multirow[t]{2}{*}{ Lag_ROA } & -6.03 & $-7.22 *$ & $-7.41 *$ \\
\hline & $(-1.53)$ & $(-1.81)$ & $(-1.90)$ \\
\hline \multirow[t]{2}{*}{ Ln_CEOTenure } & $-0.77 * *$ & $-0.78 * *$ & $-0.77 * *$ \\
\hline & $(-2.03)$ & $(-2.07)$ & $(-2.03)$ \\
\hline \multirow[t]{2}{*}{ Top5_Shrout } & $26.19 * * *$ & $27.86^{* * *}$ & $25.93^{* * *}$ \\
\hline & (6.07) & (6.39) & (6.00) \\
\hline \multirow[t]{2}{*}{ PPILL } & $4.91 * * *$ & $5.02 * * *$ & $4.86^{* * *}$ \\
\hline & $(5.69)$ & $(5.81)$ & (5.64) \\
\hline \multirow[t]{2}{*}{ CBOARD } & -0.24 & -0.24 & -0.22 \\
\hline & $(-0.27)$ & $(-0.28)$ & $(-0.25)$ \\
\hline \multirow[t]{2}{*}{ CUMVOTE } & 0.94 & 1.06 & 0.72 \\
\hline & $(0.73)$ & $(0.83)$ & $(0.55)$ \\
\hline \multirow[t]{2}{*}{ SUPERMAJOR } & 0.60 & 0.64 & 0.89 \\
\hline & $(0.69)$ & $(0.74)$ & $(1.03)$ \\
\hline Year effect & Yes & Yes & Yes \\
\hline Industry effect & Yes & Yes & Yes \\
\hline R-squared & 0.311 & 0.311 & 0.3139 \\
\hline Observations & 2916 & 2916 & 2934 \\
\hline
\end{tabular}


Figure 1: The impact of initial value of board independence on the relation between board monitoring and the Wall Street Rule: low price informativeness.

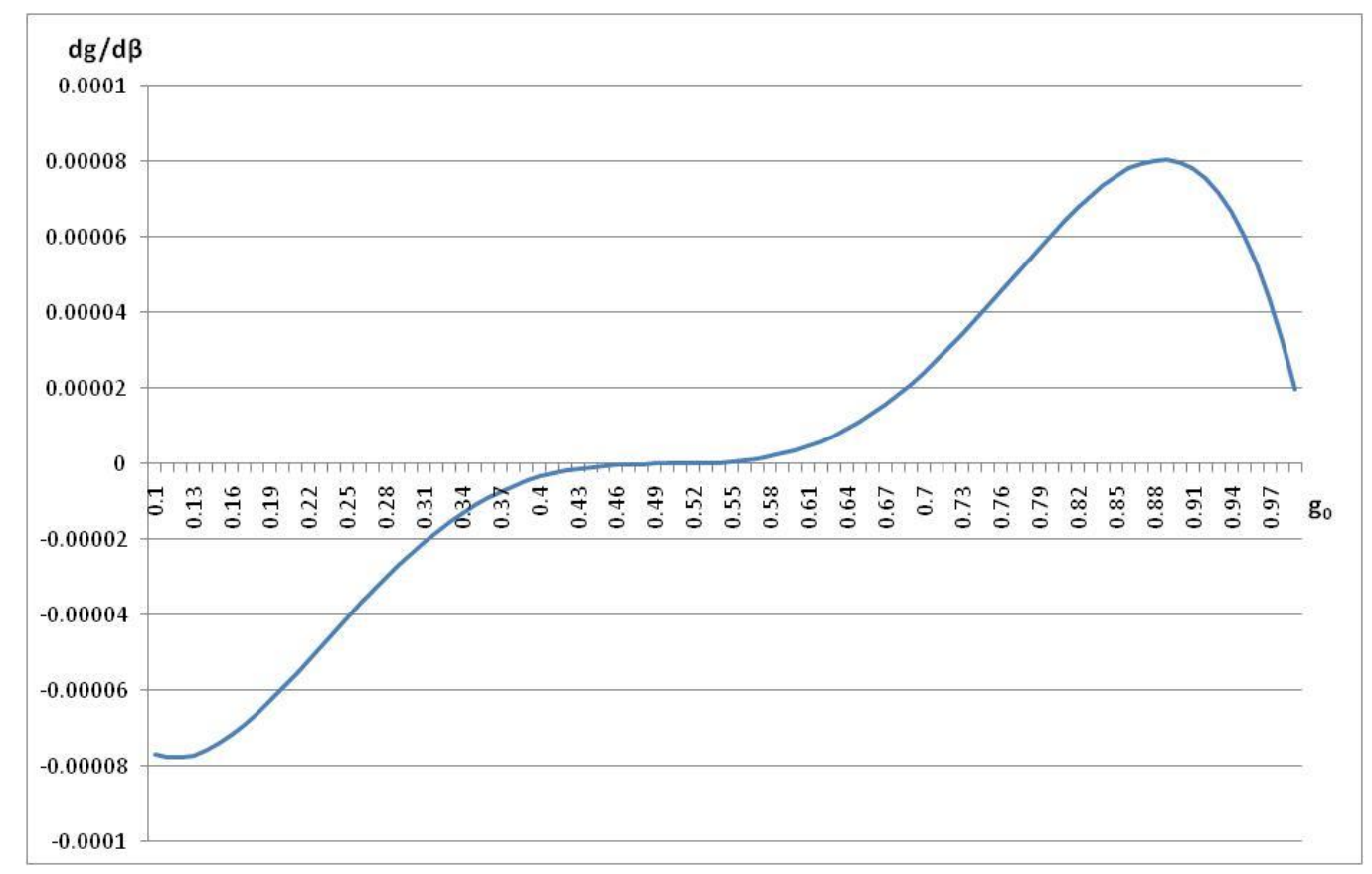

This figure shows the path of $\frac{d g}{d \beta}$ (the relation between board monitoring, $g$, and price informativeness, $\beta$ ) as the initial value of $g$ changes from 0.1 to 0.99 , by increments of 0.01 . This figure illustrates the scenario of a low level of price informativeness. The key parameter values are as follows: $\hat{\alpha}_{\hat{p}}=0.035, \rho=4, \beta=0.0006$, given that $\frac{N}{N+1}$ $=0.5, \sigma_{\varepsilon}^{2}=32.26$, and $\sigma_{\eta}^{2}=0.42$. The power of CEO's equity-based compensation $\left(\hat{\alpha}_{\hat{p}}\right)$ and the volatility of the true firm value $\left(\sigma_{\eta}^{2}\right)$ are approximated by the mean value of PPS_Total and Ret_Volat, respectively, as shown in Table 2. The manager's absolute risk aversion coefficient is set to 4 as in Haubrich (1994, pp. 274). Price informativeness ( $\beta$ ) is calculated as in equation (4), where $\frac{N}{N+1}$ is set to 0.5 to capture the scenario of low level informed trading (note that this ratio is 0.5 if there is only one informed trader), and the volatility of informed traders' observational error $\left(\sigma_{\varepsilon}^{2}\right)$ is approximated by the standard deviation of analysts' median long-term growth forecast $\left(=5.68^{2}\right)$ reported in Core, Guay, and Rusticus (2006, pp. 664). 
Figure 2: The impact of initial value of board independence on the relation between board monitoring and the Wall Street Rule: high price informativeness.

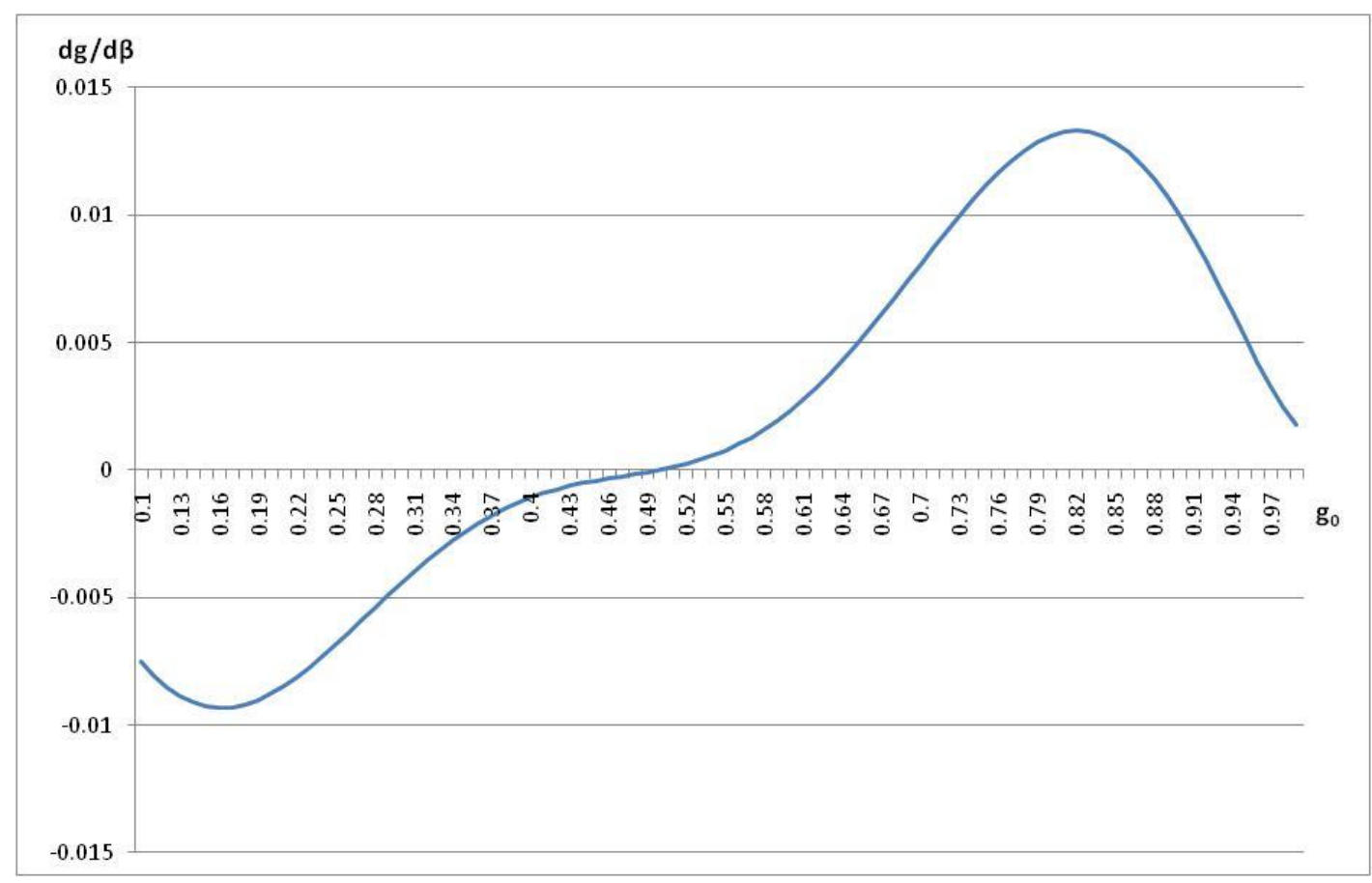

This figure shows the path of $\frac{d g}{d \beta}$ (the relation between board monitoring, $g$, and price informativeness, $\beta$ ) as the initial value of $g$ changes from 0.1 to 0.99 , by increments of 0.01 . This figure illustrates the scenario of a high level of price informativeness. The key parameter values are as follows: $\hat{\alpha}_{\hat{p}}=0.035, \rho=4, \beta=0.055$, given that $\frac{N}{N+1}=0.9, \sigma_{\varepsilon}^{2}=32.26$, and $\sigma_{\eta}^{2}=0.42$. The power of CEO's equity-based compensation $\left(\hat{\alpha}_{\hat{p}}\right)$ and the volatility of the true firm value $\left(\sigma_{\eta}^{2}\right)$ are approximated by the mean value of PPS_Total and Ret_Volat, respectively, as shown in Table 2. The manager's absolute risk aversion coefficient is set to 4 as in Haubrich (1994, pp. 274). Price informativeness ( $\beta$ ) is calculated as in equation (4), where $\frac{N}{N+1}$ is set to 0.9 to capture the scenario of high level informed trading (note that this ratio is 0.5 if there is only one informed trader), and the volatility of informed traders' observational error $\left(\sigma_{\varepsilon}^{2}\right)$ is approximated by the standard deviation of analysts' median long-term growth forecast $\left(=5.68^{2}\right)$ reported in Core, Guay, and Rusticus (2006, pp. 664). 